Article

\title{
Surface Area Evaluation of Electrically Conductive Polymer-Based Textiles
}

\author{
Lukas Vojtech ${ }^{1}$, Marek Neruda ${ }^{1}$, Tomas Reichl ${ }^{2, *}$, Karel Dusek $^{2}$ \\ and Cristina de la Torre Megías ${ }^{1}$ \\ 1 Department of Telecommunication Engineering, Faculty of Electrical Engineering, Czech Technical \\ University in Prague, 16627 Prague, Czech Republic; vojtecl@fel.cvut.cz (L.V.); nerudmar@fel.cvut.cz (M.N.); \\ cristinatm07@gmail.com (C.d.1.T.M.) \\ 2 Department of Electrotechnology, Faculty of Electrical Engineering, Czech Technical University in Prague, \\ 16627 Prague, Czech Republic; dusekk1@fel.cvut.cz \\ * Correspondence: reichto3@fel.cvut.cz; Tel.: +420-224-352-167
}

Received: 13 August 2018; Accepted: 9 October 2018; Published: 10 October 2018

check for updates

\begin{abstract}
In this paper, the surface area of coated polymer-based textiles, i.e., copper and nickel plated woven polyester fabric, copper and acrylic coated woven polyester fabric, and copper and acrylic coated non-woven polyamide fabric, is investigated. In order to evaluate the surface area of the woven fabrics, Peirce's geometrical model of the interlacing point and measurement using an electron microscope are used. Non-woven fabrics are evaluated using an optical method, handmade method, and MATLAB functions. An electrochemical method, based on the measurement of the resistance between two electrodes, is used for relative comparison of the effective surface area of the coated woven and non-woven fabrics. The experimental results show that the measured and calculated warp lengths do not differ within the standard deviation. The model for the surface area evaluation of the Pierce's geometrical model for monofilament (non-fibrous) yarns is extended to multifilament yarns and to a uniform sample size. The experimental results show the increasing trend of surface area evaluation using both modeling and electrochemical methods, i.e., the surface area of the copper and acrylic coated woven Polyester fabric (PES) is the smallest surface area of investigated samples, followed by the surface area of the copper and acrylic coated non-woven fabric, and by copper and nickel plated woven PES fabric. These methods can be used for surface area evaluation of coated polymer-based textiles in the development of supercapacitors, electrochemical cells, or electrochemical catalysts.
\end{abstract}

Keywords: electrically conductive textiles; polymers; smart textiles; surface area evaluation

\section{Introduction}

Electrically conductive textile materials have attracted considerable attention from the scientific community and have found their use in many applications. These materials are used in shielding against electromagnetic radiation, e.g., protective clothing, cable shielding, shielding of high frequency sources, etc. [1-5], in development of textile antennas [6-8] and sensors, e.g., textile sensor for Electrocardiography monitoring (ECG), and pressure and humidity sensors [9-11], as well as in the development of other electrical components and devices, e.g., supercapacitors, electrochemical cells, electrochemical catalysts, etc. [12-14].

There are many ways to improve the parameters of the last mentioned components [15]. The reduction of the internal resistance decreases the thermal loss, increases the capacity of electrochemical cells, and causes a better current distribution. One of the possible ways to reduce the internal resistance is to increase the relative effective surface area in 3-D of the sub-parts of these 
components (electrodes), i.e., the enlargement of the reaction area upon which the chemical reactions occur. It will result in greater electrochemical interconnection between the electrode and the electrolyte. In electrochemical catalysts, the increase of surface area, i.e., reaction area, causes a larger reaction area to be available during the chemical reaction, e.g., in fuel cells. In supercapacitors, the increase of surface area increases the capacity [15].

The surface area, i.e., reaction area, can be increased by using electrically conductive polymer-based textiles. The electrically conductive polymer-based textiles are an interesting class of materials that combine some mechanical properties of polymers with electrical properties typical of metals [16]. This is especially true for conductivity and permanence in applications where the chemical process takes place $[15,16]$. Additionally, these polymers have become popular because they are lightweight and economical, and have relatively high adjustable electrical conductivity, flexibility, chemical stability, and biocompatibility. The biggest advantage of conductive polymers is their processability [16]. For the future construction and engineering of the mentioned components, it is necessary to know the value of the surface area of their sub-parts. This is typically in the form of a grid, expanded metal, or plate-shaped. However, the shape of the surface area of the electrically conductive polymer-based textile, e.g., coated polymer textile, is not a typical one. The method most commonly used to determine the specific area of a solid porous substance is the Brunaer, Emmett, and Teller method (BET) $[17,18]$. This method relies on the BET equation for specific isothermal gas adsorption [17]. Although the BET method remains a popular choice for assessing the specific surface areas of nanostructured materials [18], it is speculated that BET does not provide a true representation of the geometric area. It is known that the applicability of the BET method to the porosity characterization is problematic because it is unable to capture complex adsorption mechanisms due to microporous effects [18]. BET regions are highly susceptible to the size of pores, heterogeneity of structures, and adsorbent-adsorbent interactions. There is no simple correlation between BET and geometric surface areas of nanoporous materials [18].

In this paper, three different coated polymer-based textiles, i.e., copper and nickel plated woven polyester (PES) fabric, copper and acrylic coated woven PES fabric, and copper and acrylic coated non-woven polyamide fabric, are tested for the surface area evaluation. The arrangement of the fiber in the woven fabric is investigated using the Peirce's geometrical model of the interlacing point. This model can be applicable for calculation of the surface area of monofilament (non-fibrous) yarns. The model for surface area evaluation of the multifilament yarns of woven fabric is calculated from the theoretical lengths of yarns, which are obtained by means of an electron microscope. Three methods are used for evaluation of the surface area of non-woven fabrics, i.e., handmade selection method, automatic image conversion to binary method, and threshold selection method. Results are compared with an electrochemical method, which is based on measurement of resistance between two immersed electrodes inside an electrolyte. These methods evaluate the 3-D surface area of the coated polymer-based textiles and can be used in the development of electrical and electrochemical components and devices such as supercapacitors, electrochemical cells, or electrochemical catalysts. The knowledge of surface area evaluation of a conductive 3-D layer of coated textiles can help in adjusting the weight, energy density, and capacity of these future components and equipment.

\section{Materials and Methods}

Three different types of polymer fabrics were tested, i.e., two types of woven fabrics and one type of nonwoven fabric, Table 1. CerexCuIv4 is a copper- and acrylic-coated non-woven fabric with a raw material Polyamide Cerex fabric $36 \mathrm{~g} / \mathrm{m}^{2}$ and surface resistivity $0.02 \mathrm{ohm} /$ square [19]. $\mathrm{RSKCu}+\mathrm{Ni}$ is a copper- and nickel-plated woven PES fabric with a plain weave (parachute silk) and a surface resistivity $0.02 \mathrm{ohm} /$ square [20]. RSKCuIv4 is a copper- and acrylic-coated woven PES fabric with a plain weave (parachute silk) and a surface resistivity $0.05 \mathrm{ohm} /$ square [20]. Samples were examined using a scanning electron microscope (Phenom pro $X$ ThermoFisher SCIENTIFIC, Eindhoven, The Netherlands). 
Table 1. Specifications of the used commercial polymer coated fabrics [20].

\begin{tabular}{cccc}
\hline $\begin{array}{c}\text { Material as Named by } \\
\text { the Producer/Producer }\end{array}$ & Description & Surface Resistivity & Note \\
\hline $\begin{array}{c}\text { CerexCuIv4/LORIX Ltd., } \\
\text { Budapest, Hungary }\end{array}$ & $\begin{array}{c}\text { copper + acrylic coated } \\
\text { non-woven fabric }\end{array}$ & $\begin{array}{c}\text { max avg. } 0.02 \\
\text { ohm/square }\end{array}$ & $\begin{array}{c}\text { Raw material: Polyamide } \\
\text { Cerex fabric } 36 \mathrm{~g} / \mathrm{m}^{2}\end{array}$ \\
\hline $\begin{array}{c}\text { RSKCu+Ni/LORIX Ltd., } \\
\text { Budapest, Hungary }\end{array}$ & $\begin{array}{c}\text { copper + nickel plated } \\
\text { woven PES fabric }\end{array}$ & $\begin{array}{c}\text { max avg. } 0.02 \\
\text { ohm/square }\end{array}$ & $\begin{array}{c}\text { Weave: plain weave } \\
\text { (parachute silk) }\end{array}$ \\
\hline $\begin{array}{c}\text { RSKCuIv4/LORIX Ltd., } \\
\text { Budapest, Hungary }\end{array}$ & $\begin{array}{c}\text { copper + acrylic coated } \\
\text { woven PES fabric }\end{array}$ & $\begin{array}{c}\text { max avg. } 0.05 \\
\text { ohm/square }\end{array}$ & $\begin{array}{c}\text { Weave: plain weave } \\
\text { (parachute silk) }\end{array}$ \\
\hline
\end{tabular}

\subsection{Theory of Peirce's Geometrical Model of the Interlacing Point}

The arrangement of the fiber in the fabric can be mathematically described in several ways. The simplest, but fully satisfactory, is the so-called the Peirce's geometrical model of the interlacing point [21,22] (Figure 1). This model describes the fiber as a system of a regular repeating part of a torus (a body formed by rotating a circle around a straight line) and a cylinder of height $d$. The disadvantage of the Peirce's geometrical model of the interlacing point is that it neglects the deformation of the fiber caused by forces that act on the fibers, such that shape of the fiber is always circular [21,22]. The main reason for using this model is a satisfactory balance between the efficiency of using it and its accuracy [22].

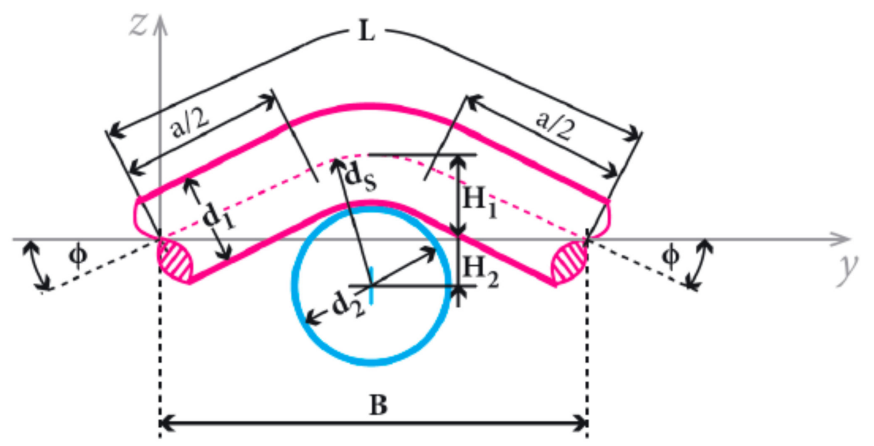

Figure 1. Peirce's geometrical model of the interlacing point [22]. Legend: $a$ is the length of the line connecting the arcs, $d_{1}$ is the diameter of the warp, $d_{2}$ is the diameter of the weft, $d_{\mathrm{s}}$ is the sum of radii of the warp and weft yarns, $H_{1}$ is the height of warp interlacing wave, $H_{2}$ is the height of weft interlacing wave, $B$ is the spacing of weft yarns, $\Phi$ is the warp interlacing angle, and $L$ is the length of warp yarn.

The relationship between the warp interlacing angle $\Phi$ and other geometric parameters (spacing of weft yarns $B$, height of the warp interlacing wave $H_{1}$, and the sum of radii of the warp and weft yarns $d_{\mathrm{S}}$ ) can be expressed using Equations (1) and (2) resulting from the section in the $y$-axis Equation (1) and in the $z$-axis Equation (2) [22]:

$$
\begin{gathered}
2 \cdot d_{\mathrm{S}} \cdot \sin (\Phi)+a \cdot \cos (\Phi)=B \\
2 \cdot d_{\mathrm{S}} \cdot[1-\cos (\Phi)]+a \cdot \sin (\Phi)=2 \cdot H_{1}
\end{gathered}
$$

The sum of the radii of the warp and weft yarns $d_{\mathrm{S}}$ is calculated using Equation (3), Figure 1:

$$
d_{\mathrm{S}}=\left(d_{1}+d_{2}\right) / 2
$$


Combining Equations (1) and (2), a quadratic equation for the warp interlacing angle $\Phi$ is obtained, as shown in Equation (4):

$$
\left[B^{2}+4 \cdot\left(H_{1}-d_{\mathrm{S}}\right)^{2}\right] \cdot \cos ^{2}(\Phi)+8 \cdot d_{\mathrm{S}} \cdot\left(H_{1}-d_{S}\right) \cdot \cos (\Phi)+\left(4 \cdot d_{\mathrm{S}}^{2}-B^{2}\right)=0
$$

The warp interlacing angle $\Phi$ can be expressed from Equation (4) as in Reference [23], given here as Equation (5):

$$
\Phi=\arccos \frac{2 M d \pm 16 r^{2}}{2\left(M^{2}+4 r^{2}\right)}
$$

where $M$ is the spacing of yarns, $r$ is the radius of yarns, and $d$ is the height of cylinder of yarns.

The height of the cylinder of yarns $d$ is then calculated using Equation (6):

$$
d=\sqrt{M^{2}-12 r^{2}}
$$

The theoretical length of the warp $L_{\text {WARP }}$ and weft $L_{\text {WEFT }}$ is calculated using Equations (7) and (8):

$$
\begin{aligned}
& L_{\text {WARP }}=2 \cdot d_{S} \cdot \Phi+a_{\text {WARP }} \\
& L_{W E F T}=2 \cdot d_{S} \cdot \Phi+a_{\text {WEFT }}
\end{aligned}
$$

where $a_{\mathrm{WARP}}$ is the length of the line connecting the arcs in warp, $a_{\mathrm{WEFT}}$ is the length of the line connecting the arcs in weft.

\subsection{Surface Area Evaluation Based on Peirce's Geometrical Model of the Interlacing Point}

To calculate the effective surface area of the conductive fabrics, i.e., the surface area that is involved in chemical reactions, the warp and weft lengths of Pierce's geometrical model of the interlacing point are first determined. The theoretical length of weft and warp are calculated from Equations (7) and (8). The length of the line connecting the arcs, diameter of warp, and diameter of weft are measured by means of an electron microscope, Phenom pro X (ThermoFisher SCIENTIFIC). From Equations (5) and (6), we obtain the warp interlacing angle and weft angle. These angles are substituted into Equations (7) and (8), which gives the theoretical length of the warp and weft. The surface area of the warp and weft is then calculated using Equations (9) and (10):

$$
\begin{aligned}
& S_{\mathrm{WARP}}=2 \pi r_{1} L_{\text {WARP }} \\
& S_{\mathrm{WEFT}}=2 \pi r_{2} L_{\text {WEFT }}
\end{aligned}
$$

The surface area of the interlacing points is calculated using Equation (11):

$$
S_{\text {Inter_Point }}=2 \pi r_{1} r_{2}
$$

The surface area of the investigated Pierce's geometrical model of the interlacing point of the textile is a sum of the warp and weft surface area, from which the surface area of interlacing points is subtracted (Equation (12)). The obtained value is then divided by two due to the $50 \%$ of the depth efficiency of the electrochemical process, which is related to the object used in the fabric structure. This ratio will be different for the electrochemical reaction and electrolyzer construction in practice. For comparison of examined methods, the ratio $50 \%$ is chosen, i.e., "visible part of the surface area" during the observation of the structure in the direction of the $z$-axis is considered.

$$
S_{\text {Effect }}=\left(S_{\text {WARP }}+S_{\text {WEFT }}\right) / 2-S_{\text {Inter_Point }}
$$


Equation (12) can be applicable for the calculation of the surface area of monofilament (non-fibrous) yarns. The surface area of multifilament yarns in warp $S_{1}$ is obtained by multiplying the theoretical length of the warp $L_{W A R P}$ and the width in weft $b$ and coefficient $K$, which takes into account the amorphousness of the fibers, as seen in Equation (13):

$$
S_{1}=L_{\mathrm{WARP}} \cdot b \cdot K
$$

where $S_{1}$ is the surface area of the multifilament yarns in warp, $b$ is the width in weft, and $K$ is the coefficient amorphousness of the fibers.

The same procedure as for $S_{1}$ is used to calculate the surface area of the multifilament yarns in weft $S_{2}$, as seen in Equation (14):

$$
S_{2}=L_{\mathrm{WEFT}} \cdot c \cdot K
$$

where $c$ is the width in warp.

The $K$ is calculated as the ratio of the width of the multifilament yarns $K_{\text {straight }}$ and the length of coating of multifilament yarns in cross-section $K_{\text {curve, }}$ which is shown in Figure 2 and given in Equation (15). The difference in the shape of the yarns, i.e., difference between elliptical shape of yarns as assumed by the Pierce's geometrical model of the interlacing point and the real shape of yarns as shown in Figure 2, is assumed to be negligible. This assumption is verified in Section 3.2 (Table 7) and Section 3.3 (Table 12).

$$
K=\frac{K_{\text {curve }}}{K_{\text {straight }}}
$$

where $K_{\text {straight }}$ is the width of the multifilament yarns and $K_{\text {curve }}$ is the length of the coating of multifilament yarns in cross-section.

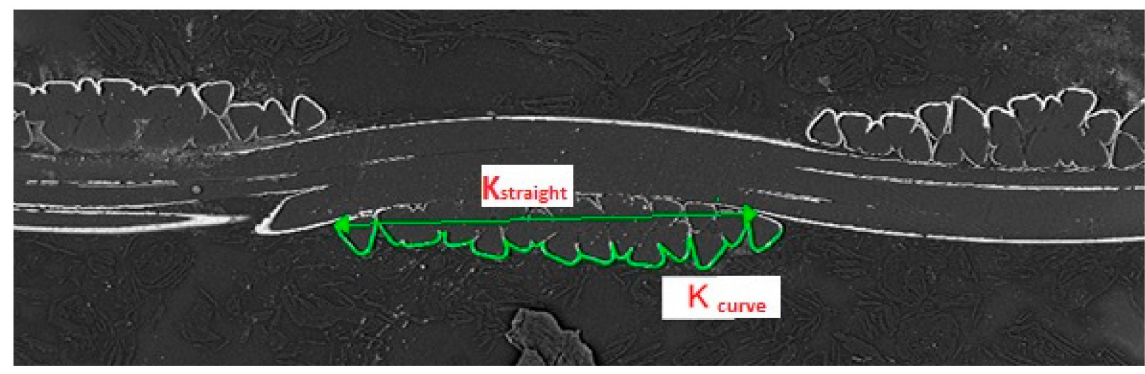

Figure 2. Evaluation of the width of the multifilament yarns $K_{\text {straight }}$ and the length of coating of multifilament yarns in cross-section $K_{\text {curve }}$.

\subsection{Optical Method for the Non-Woven Fabric Evaluation}

\subsubsection{Handmade Selection Method}

One of the methods used for surface area evaluation is a time-consuming handmade selection method. It is based on choosing all fibers individually by hand in the obtained picture from the electron microscope image (Figure 3). It illustrates individual fibers and the background, represented by the light and dark areas, respectively.

The white bar that is given at the bottom of the picture is used as a reference value in $\mu \mathrm{m}$ to match the measured length of each fiber. For this reason, the length of this scale bar has to be saved as a variable. The measurement of the scale bar is accomplished by selecting the length of the bar each time the method is executed. It is carried out with the function of MATLAB "imline" [24].

Once the bar length is selected, the diameter of one fiber is selected by hand [24]. We assume the diameter is the same in all fibers. Therefore, fiber selection for measuring the diameter does not have the relevance. To increase accuracy, it is recommended to follow these two recommendations:

- Select the diameter in the upper fibers, which are sharper than the rest. 
- Choose fibers that are directly in contact with the background since the boundaries of these fibers can be differentiated more easily.

After this, a line that covers the whole length of each fiber is traced to obtain the fiber length. It is important to take into account that the lines are determined by hand, using the function "imfreehand" of MATLAB [25]. Lines are drawn in the center of every fiber with the highest precision the user can perform.

Next, the length of the fiber and the diameter are compared with the scale bar length and the area is calculated using the known mathematical equation for the volume of a cylinder, i.e., half of 3-D surface area is calculated [26]. Finally, the total area is the sum of the area of all fibers.

As it can be appreciated in the described method, accuracy of the length measurements depend on the user. At least lengths referring to the bar and diameter are straight lines and are taken only once, but every fiber length is completely determined by hand, which increases the error. This error can be mitigated by creating a function that calculates the exact points of the center of the yarn. It must also be taken into account that the mistake that may appear in the selection of fibers that are missing in each step, i.e., the user can forget some fibers or parts of them that seem part of background.

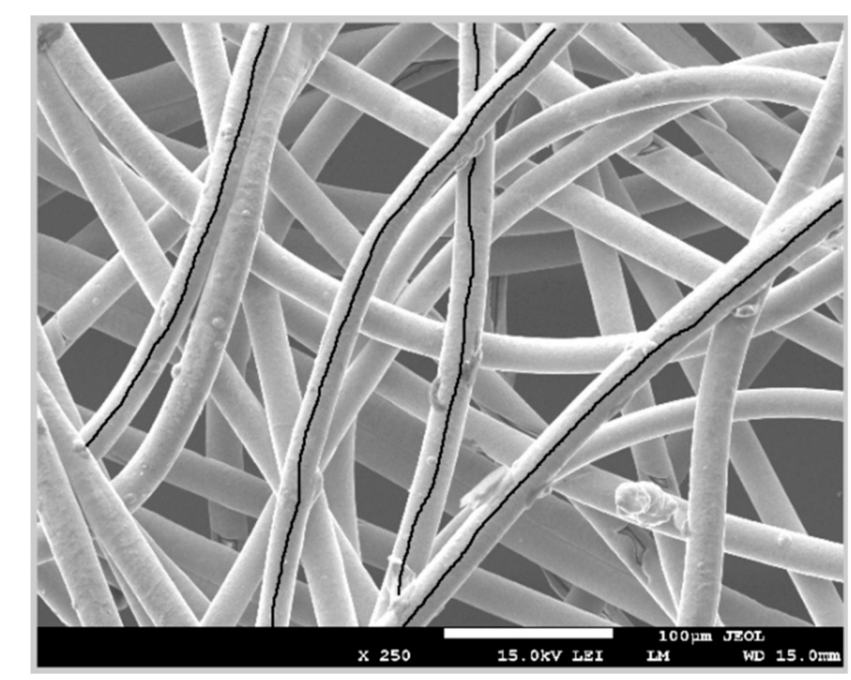

Figure 3. Selection of the fiber lengths by hand.

\subsubsection{Automatic Image Conversion to Binary}

Another method for the surface area evaluation of non-woven fabrics is the conversion of the obtained microscope picture of the sample to a binary image. It consists of changing all fibers to white and the background to black to differentiate clearly which parts of the image are conductive.

The same sample is used for the surface area evaluation as described in the previous section. As per the previous method, the length of scale bar is measured by hand. However, the used standard MATLAB function "imtool" provides the possibility to check the value of the pixels, 0 (black) or 255 (white) [27]. When the user selects the length manually, they check the pixel value at the same time. If it is white, the user starts to measure the length and stops the measurement when they see the change from 255 to 0 .

The procedure of the diameter measurement is the same as the bar measurement. The user can appreciate how the intensity of gray varies, since white values of pixels are higher than black values, therefore the user knows when to start and stop the measurement. As explained in the previous section, the diameter is selected according to the two described recommendations.

After that, the original image is converted to a binary image (Figure 4). The input image is converted to a grayscale format (if it is not already an intensity image), and then to binary. This procedure is directly performed using the function "im2bw (I, 0.5$)$ ". 
Next, the user selects the part of image that contains fibers, and pixels in white are counted [28]. In case two consecutive pixels are white, the distance between them is calculated and saved into a variable. This variable, and also the diameter, are compared with the scale bar, and then the area is calculated using the same equation as in the previous method.

As shown in Figure 4, when the image is converted to binary, not all the fibers are completely white, which is the main cause of the error in this method. In this case the improved function consists of delimiting the boundaries of all fibers and fills the pixels inside these limits. Therefore, pixels inside fibers that are not in white using function "im $2 \mathrm{bw}$ " will be converted using this improved function. The other cause comes from the user when the user takes measurements of the scale bar and diameter. Another source of error appears when the image is cropped. The user can make a mistake if they select a smaller size of the required image [28].

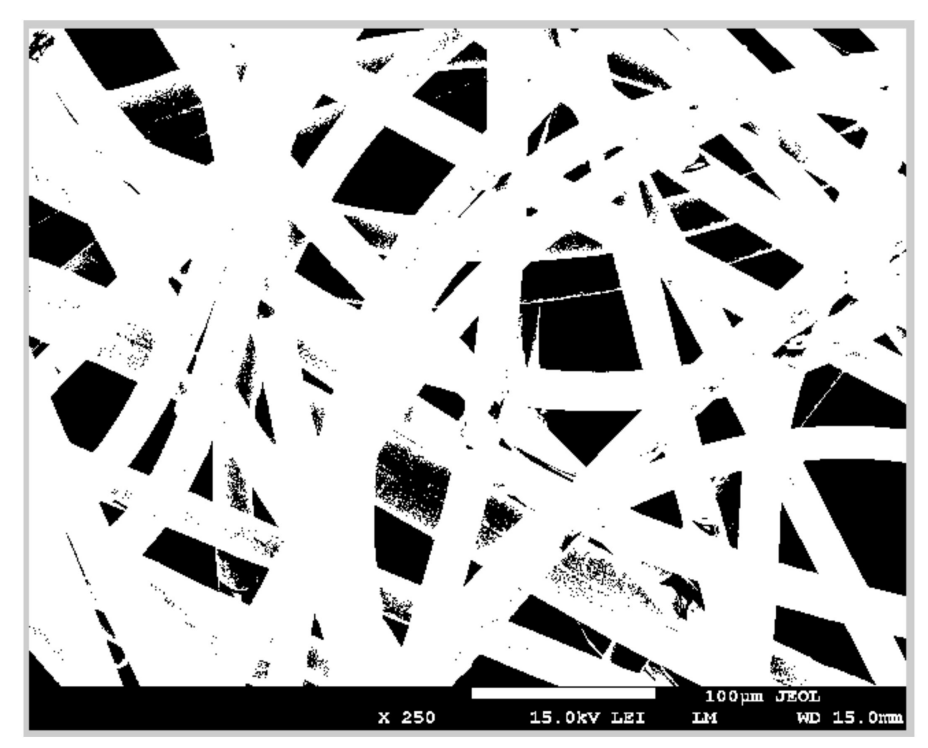

Figure 4. Binary image.

\subsubsection{Threshold Selection Method}

The third method used for evaluating the surface area of non-woven fabrics is the transformation of the color of the background using thresholding. This method is based on finding the appropriate threshold in the gray scale to change the background pixels to black. Therefore, the fibers can be seen more clearly in the image. The same image sample is used as in the previous cases (Figure 3). Measurement of the scale bar and diameter is performed according to the same procedure as in the previous method, i.e., the function "imtool" is used.

When the measured values of the length of the scale bar and diameter are saved, the image is cropped to work only with the part that contains the fibers. The difference between this method and previous one is that the original image is not converted to binary. In this case, a threshold is used whose value can be changed to achieve the best results. The background color is changed to black to check the amount of pixels that are considered background (Figure 5). 


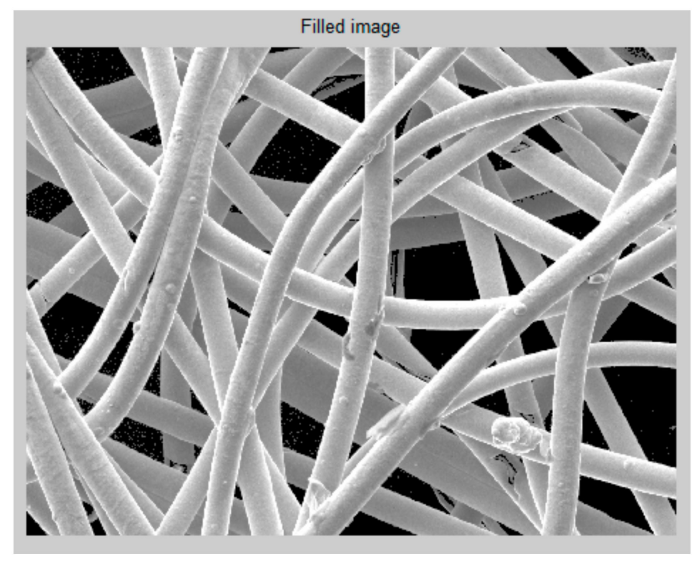

Figure 5. Filled image using a threshold to change the background color.

As can be seen from Figure 5, some parts inside the fibers are painted in black because they are darker, such that the threshold condition is met due to deformation of the fiber. On the contrary, not all parts of the background are painted in black because all backgrounds do not have the same color or the same intensity of black color. This is a major error for this method and should also be considered a user-side error as described in the previous method. In conclusion, the preferred method is the threshold selection method, due to its higher accuracy and lower assistance requirement from the user.

\subsection{Experimental Electrochemical Method for Surface Area Evaluation}

The surface area of the coated woven and non-woven fabrics can be also evaluated using an electrochemical method, based on the measurement of the resistance between two electrodes. This method is effective, i.e., easy to use, for the relative comparison of surface area values, and is not suitable for a total surface area evaluation for several reasons. The contact resistance error, i.e., systematic error, is eliminated by comparative measurement. The electrode polarization errors are eliminated by using an alternating current and a small current $(\mathrm{i}<100 \mu \mathrm{A})$. Chemical changes of the electrolyte are eliminated by the low conductivity of the electrolyte, the small current used, and by the high volume of electrolyte. The conductivity of the metal coating of textiles is much higher than the conductivity of the electrolyte $\left(\mathrm{H}_{2} \mathrm{O}\right)$, therefore the voltage drop in the electrolyte is much higher than the voltage drop on the coated fabric, and thus different coatings of the textiles can be neglected. The electrodes are placed in a plastic holder that is immersed into the electrolyte $\left(\mathrm{H}_{2} \mathrm{O}\right.$, with temperature $25^{\circ} \mathrm{C}$ ). The first (base) electrode is fixed in a stable position in a plastic holder. The material of this electrode is a $\mathrm{Cu}$ plate, i.e., fully copper-plated printed circuit board with a surface area of copper $3.06 \times 10^{-3} \mathrm{~m}^{2}$. It is chosen because of a good surface flatness and negligible thickness of the conductive copper layer. The following four types of the second electrode are used:

- $\quad \mathrm{Cu}$ plate (same sample properties as the first (base) electrode)

- CerexCuIv4

- $\quad \mathrm{RSKCu}+\mathrm{Ni}$

- $\quad$ RSKCuIv4

In case of fabric samples, the samples were stuck on non-conductive plate using double-sided adhesive tape. The size of the surface area of all electrodes was the same, i.e., $3.06 \times 10^{-3}$ $\mathrm{m}^{2}$. An immersed plastic holder with electrodes inside the electrolyte is shown in Figure 6 . The distance between the electrodes is changed during the measurement of resistance between electrodes. The resistance is measured by Battery Analyzer, $60 \mathrm{~V}$ Battery Analyzer BA6010 (BK Precision, Yorba Linda, CA, USA) at $1 \times 10^{3} \mathrm{~Hz}$ for three different distances between electrodes, i.e., $0.03,0.04$, and $0.05 \mathrm{~m}$. 
Comparison of the surface area of samples was based on the electrolyte resistivity constant and the distance between the electrodes:

$$
R \cdot S=\rho \cdot l=\text { const. }
$$

where $R$ is the measured resistance, $S$ is the surface area, $\rho$ is the resistivity of electrolyte, and $l$ is the distance between electrodes.

Equation (16) shows the comparison of the surface area of samples was relative, i.e., it identifies the larger or smaller surface area in comparison with other samples. This comparative measurement method eliminates systematic errors.

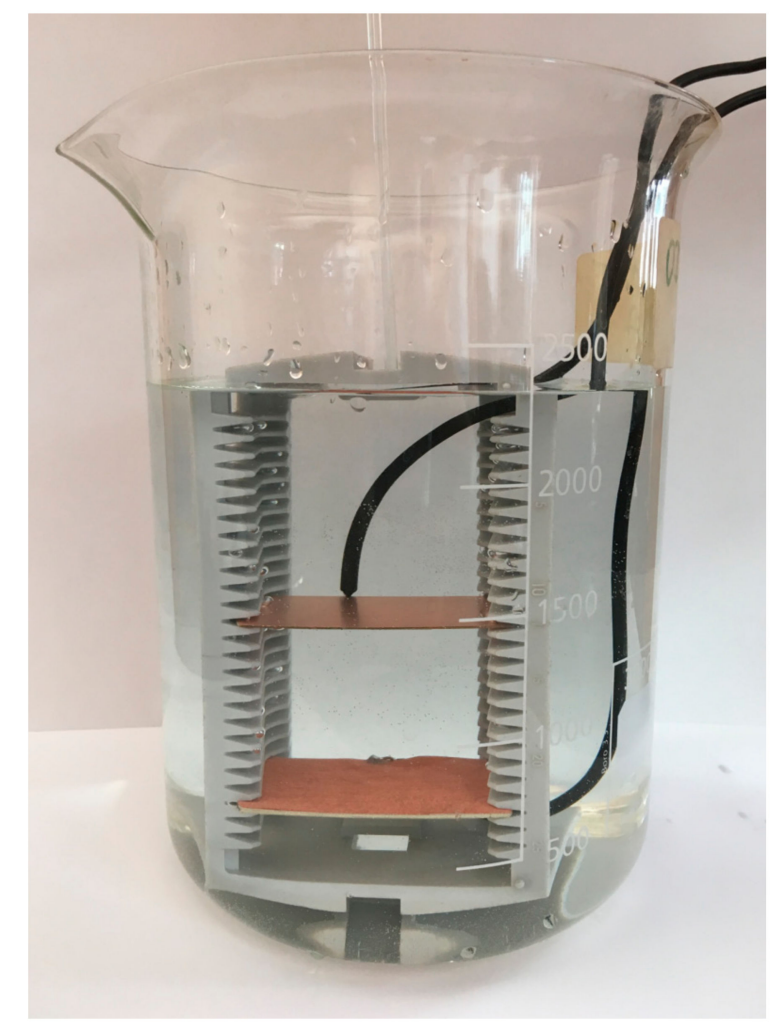

Figure 6. Immersed plastic holder with electrodes inside the electrolyte to give a measurement of the resistance between two electrodes.

\section{Results and Discussion}

\subsection{Surface Area Evaluation of CerexCuIv4}

The surface area of CerexCuIv4, i.e., coated non-woven fabric, was evaluated by the optical method described in Section 2.3. Figure 7 shows a detail of a sample, which was used for the calculation of the effective surface area. The results are shown for a handmade selection method in Table 2, for the automatic image conversion to binary method in Table 3, and for the threshold selection method in Table 4. The surface area evaluated by the handmade selection method was $2.67 \times 10^{-7} \pm 1.89 \times 10^{-8} \mathrm{~m}^{2}$, by automatic image conversion to binary method was $2.30 \times 10^{-7} \pm 1.49 \times 10^{-8} \mathrm{~m}^{2}$, and using the threshold selection method was $2.70 \times 10^{-7} \pm 1.60 \times 10^{-8} \mathrm{~m}^{2}$. 


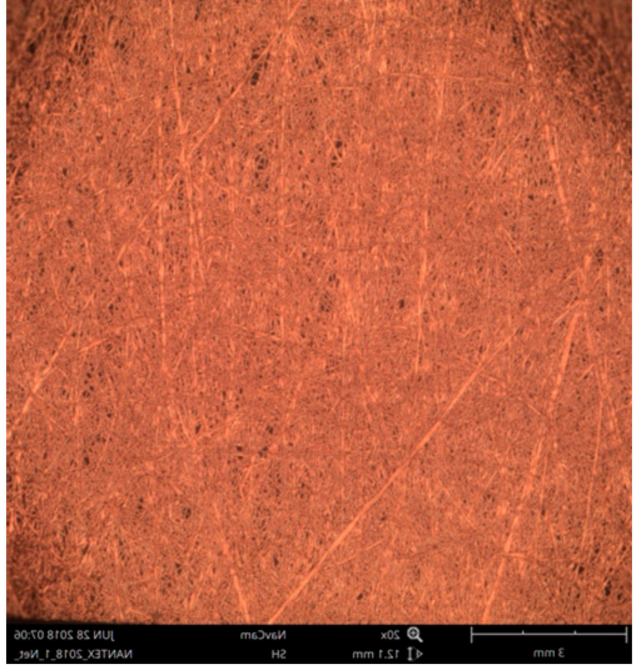

(a)

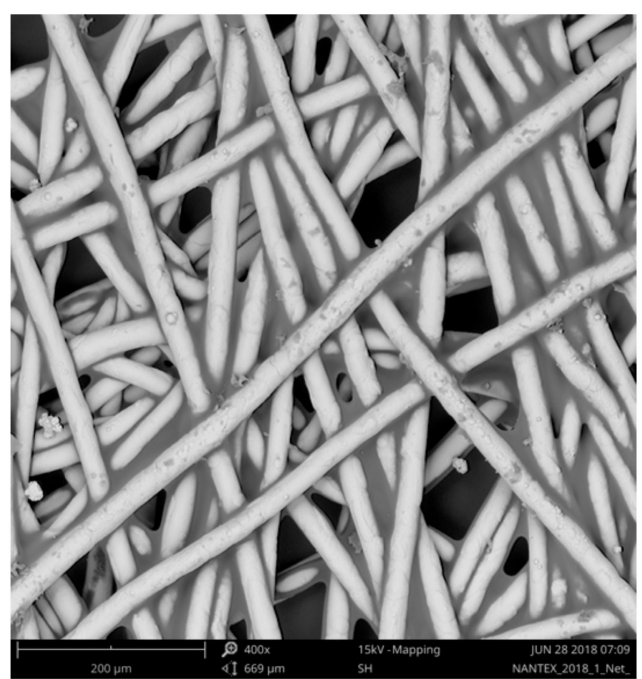

(b)

Figure 7. A sample of CerexCuIv4 (coated non-woven fabric) (a), and detail of the sample structure (b).

Table 2. Results for the handmade selection method.

\begin{tabular}{cc}
\hline Parameter & Average $^{\mathbf{1}}$ \\
\hline Scale bar (pxs) & $2.66 \times 10^{2}$ \\
Diameter (pxs) & $5.82 \times 10^{1}$ \\
Surface area $\left(\mathrm{m}^{2}\right)$ & $2.67 \times 10^{-7}$ \\
Surface area standard deviation $\sigma\left(\mathrm{m}^{2}\right)$ & $1.89 \times 10^{-8}$ \\
\hline
\end{tabular}

${ }^{1}$ Number of measurements: 10.

Table 3. Results for automatic image conversion to binary method.

\begin{tabular}{cc}
\hline Parameters & Average $^{\mathbf{1}}$ \\
\hline Scale bar (pxs) & $2.66 \times 10^{2}$ \\
Diameter (pxs) & $5.61 \times 10^{1}$ \\
Surface area (m $\left.{ }^{2}\right)$ & $2.30 \times 10^{-7}$ \\
Surface area standard deviation $\sigma\left(\mathrm{m}^{2}\right)$ & $1.49 \times 10^{-8}$
\end{tabular}

${ }^{1}$ Number of measurements: 10 .

Table 4. Results for threshold selection method.

\begin{tabular}{cc}
\hline Parameters & Average $^{\mathbf{1}}$ \\
\hline Scale bar (pxs) & $2.66 \times 10^{2}$ \\
Diameter (pxs) & $5.65 \times 10^{1}$ \\
Surface area $\left(\mathrm{m}^{2}\right)$ & $2.70 \times 10^{-7}$ \\
Surface area standard deviation $\sigma\left(\mathrm{m}^{2}\right)$ & $1.60 \times 10^{-8}$ \\
\hline
\end{tabular}

${ }^{1}$ Number of measurements: 10 .

\subsection{Surface Area Evaluation of RSKCuIv4}

The surface area of RSKCuIv4 was evaluated using the method based on Peirce's geometrical model of the interlacing point described in Sections 2.1 and 2.2 (Figure 8). 


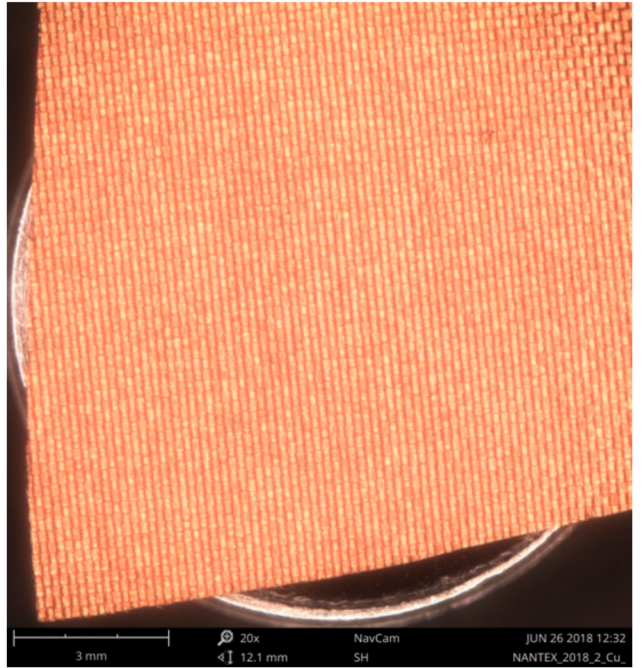

(a)

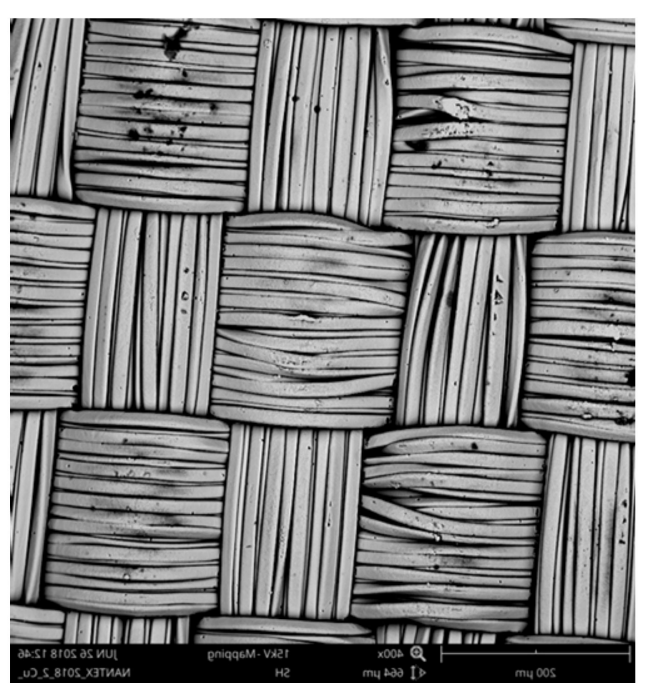

(b)

Figure 8. A sample of RSKCuIv4 (a), and detail of the sample structure (b).

Figure 9 shows the measurement of input parameters for the theoretical length of the warp and weft calculation using Equations (7) and (8). The length of the line connecting the arcs in warp and weft are marked $a$ and $b$, respectively. The sum of the radii of the warp and weft yarns $d_{\mathrm{s}}$ was obtained from measurement of diameters of the warp and weft yarns, marked $d$-warp and $d$-weft, respectively. The warp interlacing angle $\Phi$ was obtained from measurement of the spacing of yarns, marked $M$; from calculation of the height of cylinder of yarns, Equation (6), i.e., parameters $M, d$-warp, and $d$-weft were considered; and from calculation of the radius of yarns, i.e., parameters $d$-warp and $d$-weft were considered. The theoretical length of the warp $L_{\text {WARP_CALC }}$ and $L_{\text {WEFT_CALC }}$ was then calculated (Table 5). The length of the warp LWARP_MEAS was also measured (Figure 10 and Table 6).

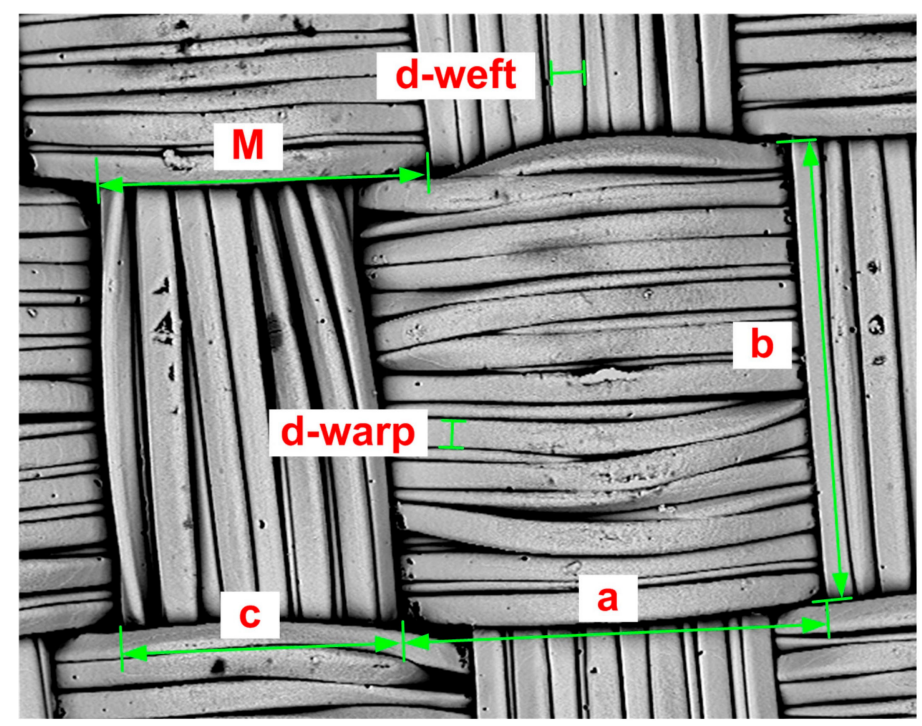

Figure 9. Measurement of input parameters for the theoretical length of the warp and weft calculation for the sample RSKCuIv4. 
Table 5. The measurement results of input parameters $a, b, c, M, d$-warp, $d$-weft, LWARP_CALC, and LWEFT_CALC-RSKCuIv4.

\begin{tabular}{ccccccccc}
\hline Meas. & $\boldsymbol{a}$ & $\boldsymbol{b}$ & $\boldsymbol{c}$ & $\boldsymbol{M}$ & $\boldsymbol{d}$-warp & $\boldsymbol{d}$-weft & LWARP_CALC & LWEFT_CALC \\
\hline No. & $\mathbf{( m )}$ & $\mathbf{( m )}$ & $\mathbf{( m )}$ & $\mathbf{( m )}$ & $\mathbf{( m )}$ & $\mathbf{( m )}$ & $\mathbf{( m )}$ \\
\hline 1 & $2.01 \times 10^{-4}$ & $2.12 \times 10^{-4}$ & $1.45 \times 10^{-4}$ & $1.55 \times 10^{-4}$ & $1.08 \times 10^{-5}$ & $1.02 \times 10^{-5}$ & $2.03 \times 10^{-4}$ & $2.13 \times 10^{-4}$ \\
2 & $2.03 \times 10^{-4}$ & $2.12 \times 10^{-4}$ & $1.44 \times 10^{-4}$ & $1.58 \times 10^{-4}$ & $1.04 \times 10^{-5}$ & $1.00 \times 10^{-5}$ & $2.04 \times 10^{-4}$ & $2.13 \times 10^{-4}$ \\
3 & $2.04 \times 10^{-4}$ & $2.12 \times 10^{-4}$ & $1.45 \times 10^{-4}$ & $1.58 \times 10^{-4}$ & $1.08 \times 10^{-5}$ & $1.08 \times 10^{-5}$ & $2.06 \times 10^{-4}$ & $2.13 \times 10^{-4}$ \\
4 & $2.02 \times 10^{-4}$ & $2.17 \times 10^{-4}$ & $1.47 \times 10^{-4}$ & $1.60 \times 10^{-4}$ & $1.08 \times 10^{-5}$ & $1.05 \times 10^{-5}$ & $2.03 \times 10^{-4}$ & $2.18 \times 10^{-4}$ \\
5 & $2.00 \times 10^{-4}$ & $2.22 \times 10^{-4}$ & $1.46 \times 10^{-4}$ & $1.59 \times 10^{-4}$ & $1.02 \times 10^{-5}$ & $1.09 \times 10^{-5}$ & $2.01 \times 10^{-4}$ & $2.23 \times 10^{-4}$ \\
6 & $2.00 \times 10^{-4}$ & $2.23 \times 10^{-4}$ & $1.47 \times 10^{-4}$ & $1.61 \times 10^{-4}$ & $1.03 \times 10^{-5}$ & $1.02 \times 10^{-5}$ & $2.01 \times 10^{-4}$ & $2.24 \times 10^{-4}$ \\
7 & $1.97 \times 10^{-4}$ & $2.25 \times 10^{-4}$ & $1.46 \times 10^{-4}$ & $1.59 \times 10^{-4}$ & $1.09 \times 10^{-5}$ & $1.00 \times 10^{-5}$ & $1.98 \times 10^{-4}$ & $2.26 \times 10^{-4}$ \\
8 & $1.96 \times 10^{-4}$ & $2.23 \times 10^{-4}$ & $1.44 \times 10^{-4}$ & $1.59 \times 10^{-4}$ & $1.08 \times 10^{-5}$ & $1.01 \times 10^{-5}$ & $1.97 \times 10^{-4}$ & $2.24 \times 10^{-4}$ \\
9 & $1.95 \times 10^{-4}$ & $2.20 \times 10^{-4}$ & $1.49 \times 10^{-4}$ & $1.60 \times 10^{-4}$ & $1.03 \times 10^{-5}$ & $1.02 \times 10^{-5}$ & $1.96 \times 10^{-4}$ & $2.21 \times 10^{-4}$ \\
10 & $1.97 \times 10^{-4}$ & $2.17 \times 10^{-4}$ & $1.45 \times 10^{-4}$ & $1.62 \times 10^{-4}$ & $1.08 \times 10^{-5}$ & $1.03 \times 10^{-5}$ & $1.98 \times 10^{-4}$ & $2.18 \times 10^{-4}$ \\
\hline Average & $2.00 \times 10^{-4}$ & $2.18 \times 10^{-4}$ & $1.46 \times 10^{-4}$ & $1.59 \times 10^{-4}$ & $1.06 \times 10^{-5}$ & $1.03 \times 10^{-5}$ & $2.01 \times 10^{-4}$ & $2.19 \times 10^{-4}$ \\
Stand. & $2.90 \times 10^{-6}$ & $4.80 \times 10^{-6}$ & $1.47 \times 10^{-6}$ & $1.80 \times 10^{-6}$ & $3.00 \times 10^{-7}$ & $3.00 \times 10^{-7}$ & $3.00 \times 10^{-6}$ & $4.70 \times 10^{-6}$ \\
deviation $\sigma$ & & & & & & & & \\
\hline
\end{tabular}

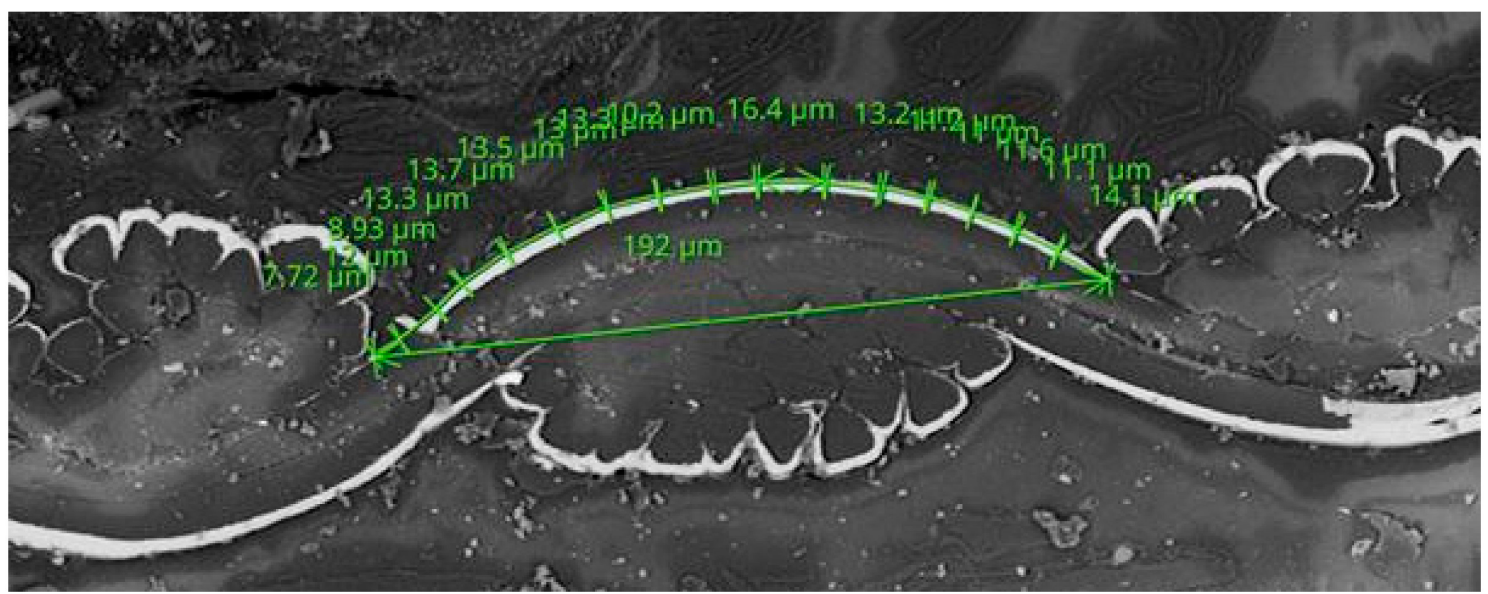

Figure 10. Measurement of the length of the warp for the sample RSKCuIv4.

Table 6. The measurement results of the length of the warp LWARP_MEAS and the length of the line connecting the arcs in warp $a$-RSKCuIv4.

\begin{tabular}{|c|c|c|c|c|c|c|c|c|}
\hline \multirow{2}{*}{ Meas. No. } & \multicolumn{6}{|c|}{ Measured Parts of the arc } & \multirow{2}{*}{$\begin{array}{c}L_{\text {warp_MEAS }} \\
(\mathrm{m})\end{array}$} & \multirow{2}{*}{$\frac{a}{(\mathrm{~m})}$} \\
\hline & \multicolumn{6}{|c|}{ (m) } & & \\
\hline \multirow{3}{*}{1} & $7.70 \times 10^{-6}$ & $1.20 \times 10^{-5}$ & $8.90 \times 10^{-6}$ & $1.33 \times 10^{-5}$ & $1.37 \times 10^{-5}$ & $1.35 \times 10^{-5}$ & \multirow{3}{*}{$2.04 \times 10^{-4}$} & \multirow{3}{*}{$1.92 \times 10^{-4}$} \\
\hline & $1.30 \times 10^{-5}$ & $1.33 \times 10^{-5}$ & $1.02 \times 10^{-5}$ & $1.44 \times 10^{-5}$ & $1.32 \times 10^{-5}$ & $1.12 \times 10^{-5}$ & & \\
\hline & $1.10 \times 10^{-5}$ & $1.16 \times 10^{-5}$ & $1.16 \times 10^{-5}$ & $1.11 \times 10^{-5}$ & $1.41 \times 10^{-5}$ & - & & \\
\hline \multirow{3}{*}{2} & $1.00 \times 10^{-5}$ & $1.30 \times 10^{-5}$ & $7.00 \times 10^{-6}$ & $1.20 \times 10^{-5}$ & $1.10 \times 10^{-5}$ & $1.40 \times 10^{-5}$ & \multirow{3}{*}{$2.06 \times 10^{-4}$} & \multirow{3}{*}{$1.93 \times 10^{-4}$} \\
\hline & $1.30 \times 10^{-5}$ & $1.12 \times 10^{-5}$ & $1.05 \times 10^{-5}$ & $1.70 \times 10^{-5}$ & $1.40 \times 10^{-5}$ & $1.30 \times 10^{-5}$ & & \\
\hline & $1.05 \times 10^{-5}$ & $1.15 \times 10^{-5}$ & $1.30 \times 10^{-5}$ & $1.30 \times 10^{-5}$ & $1.25 \times 10^{-5}$ & - & & \\
\hline \multirow{3}{*}{3} & $1.20 \times 10^{-5}$ & $1.10 \times 10^{-5}$ & $1.05 \times 10^{-5}$ & $1.30 \times 10^{-5}$ & $1.40 \times 10^{-5}$ & $1.38 \times 10^{-5}$ & \multirow{3}{*}{$2.05 \times 10^{-4}$} & \multirow{3}{*}{$1.96 \times 10^{-4}$} \\
\hline & $1.25 \times 10^{-5}$ & $1.05 \times 10^{-5}$ & $9.50 \times 10^{-6}$ & $1.45 \times 10^{-5}$ & $1.40 \times 10^{-5}$ & $1.09 \times 10^{-5}$ & & \\
\hline & $1.02 \times 10^{-5}$ & $1.10 \times 10^{-5}$ & $1.12 \times 10^{-5}$ & $1.35 \times 10^{-5}$ & $1.30 \times 10^{-5}$ & 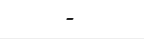 & & \\
\hline \multirow{3}{*}{4} & $1.40 \times 10^{-5}$ & $1.10 \times 10^{-5}$ & $1.35 \times 10^{-5}$ & $1.10 \times 10^{-5}$ & $1.25 \times 10^{-5}$ & $1.27 \times 10^{-5}$ & \multirow{3}{*}{$2.06 \times 10^{-4}$} & \multirow{3}{*}{$1.97 \times 10^{-4}$} \\
\hline & $1.27 \times 10^{-5}$ & $1.01 \times 10^{-5}$ & $1.37 \times 10^{-5}$ & $1.27 \times 10^{-5}$ & $1.13 \times 10^{-5}$ & $1.15 \times 10^{-5}$ & & \\
\hline & $1.05 \times 10^{-5}$ & $9.00 \times 10^{-6}$ & $1.22 \times 10^{-5}$ & $1.35 \times 10^{-5}$ & $1.22 \times 10^{-5}$ & - & & \\
\hline \multirow{3}{*}{5} & $1.30 \times 10^{-5}$ & $1.25 \times 10^{-5}$ & $1.17 \times 10^{-5}$ & $1.20 \times 10^{-5}$ & $1.27 \times 10^{-5}$ & $1.30 \times 10^{-5}$ & \multirow{3}{*}{$2.13 \times 10^{-4}$} & \multirow{3}{*}{$1.98 \times 10^{-4}$} \\
\hline & $1.40 \times 10^{-5}$ & $1.36 \times 10^{-5}$ & $1.90 \times 10^{-5}$ & $1.28 \times 10^{-5}$ & $1.30 \times 10^{-5}$ & $9.00 \times 10^{-6}$ & & \\
\hline & $1.12 \times 10^{-5}$ & $1.10 \times 10^{-5}$ & $1.28 \times 10^{-5}$ & $1.17 \times 10^{-5}$ & $9.70 \times 10^{-6}$ & - & & \\
\hline Average & - & - & - & - & - & - & $2.07 \times 10^{-4}$ & $1.95 \times 10^{-4}$ \\
\hline $\begin{array}{c}\text { Stand. } \\
\text { deviation } \sigma\end{array}$ & - & - & - & - & - & - & $3.09 \times 10^{-6}$ & $2.30 \times 10^{-6}$ \\
\hline
\end{tabular}

The theoretical warp length $L_{\text {WARP_CALC }}$ was $2.01 \times 10^{-4} \pm 3.00 \times 10^{-6} \mathrm{~m}$ and the measured warp length $L_{\text {WARP_MEAS }}$ was $2.07 \times 10^{-4} \pm 3.09 \times 10^{-6} \mathrm{~m}$. The ratio of $L_{\text {WARP_CALC }}$ and $L_{\text {WARP_MEAS }}$ is presented in Table 7. It shows the difference in the units of percentage, i.e., the deformation of the 
yarns could be neglected, thus the circular shape of cross-section of warp and weft yarns of the Peirce's geometrical model of the interlacing point could be used. The theoretical warp lengths $L_{\text {WARP_CALC }}$ and $L_{\text {WEFT_CALC }}$ were inserted in the Equations (9) and (10) to find $S_{\text {WARP }}$ and $S_{\text {WEFT }}$, respectively. The surface area of the investigated Pierce's geometrical model of the sample was then obtained using Equation (12). The surface area of the investigated multifilament model of the sample was then obtained using Equations (13) and (14) (Table 8).

Table 7. The comparison of measurement and calculated results of the length of the warp-RSKCuIv4.

\begin{tabular}{cccc}
\hline Meas. & $\boldsymbol{L}_{\text {warp_MEAS }}$ & $\boldsymbol{L}_{\text {warp_CALC }}$ & $\boldsymbol{L}_{\text {warp_MEAS }} / \boldsymbol{L}_{\text {warp_CALC }}$ \\
\hline No. & $\mathbf{( m )}$ & $\mathbf{( m )}$ & $\mathbf{( \% )}$ \\
\hline 1 & $2.04 \times 10^{-4}$ & $2.02 \times 10^{-4}$ & 100.99 \\
2 & $2.06 \times 10^{-4}$ & $2.04 \times 10^{-4}$ & 100.98 \\
3 & $2.05 \times 10^{-4}$ & $2.05 \times 10^{-4}$ & 100.00 \\
4 & $2.06 \times 10^{-4}$ & $2.03 \times 10^{-4}$ & 101.48 \\
5 & $2.13 \times 10^{-4}$ & $2.01 \times 10^{-4}$ & 105.97 \\
Average & $2.07 \times 10^{-4}$ & $2.03 \times 10^{-4}$ & 101.88 \\
Stand. deviation $\sigma$ & $3.09 \times 10^{-6}$ & $1.43 \times 10^{-6}$ & 2.10 \\
\hline
\end{tabular}

Table 8. The modeling results for RSKCuIv4.

\begin{tabular}{ccc}
\hline Parameter & Average & Standard Deviation \\
\hline$L_{\text {WARP_CALC }}(\mathrm{m})$ & $2.01 \times 10^{-4}$ & $3.00 \times 10^{-6}$ \\
$L_{\text {WEFT_CALC }}(\mathrm{m})$ & $2.19 \times 10^{-4}$ & $4.70 \times 10^{-6}$ \\
$S_{\text {WARP }}\left(\mathrm{m}^{2}\right)$ & $6.70 \times 10^{-15}$ & $1.90 \times 10^{-16}$ \\
$S_{\text {WEFT }}\left(\mathrm{m}^{2}\right)$ & $7.11 \times 10^{-15}$ & $2.40 \times 10^{-16}$ \\
$S_{\text {Inter_point }}\left(\mathrm{m}^{2}\right)$ & $1.7 \times 10^{-16}$ & $1.00 \times 10^{-17}$ \\
$S_{\text {Effect }}\left(\mathrm{m}^{2}\right)$ & $6.73 \times 10^{-15}$ & $1.30 \times 10^{-16}$ \\
S1 $_{\text {WARP_Multi }}\left(\mathrm{m}^{2}\right)$ & $6.50 \times 10^{-14}$ & $1.03 \times 10^{-15}$ \\
S2 $_{\text {WEFT_Multi }}\left(\mathrm{m}^{2}\right)$ & $4.74 \times 10^{-14}$ & $1.03 \times 10^{-15}$ \\
\hline
\end{tabular}

\subsection{Surface Area Evaluation of RSKCu+Ni}

Surface area of RSKCu+Ni was evaluated using the method based on Peirce's geometrical model of the interlacing point described in Sections 2.1 and 2.2 (Figure 11).

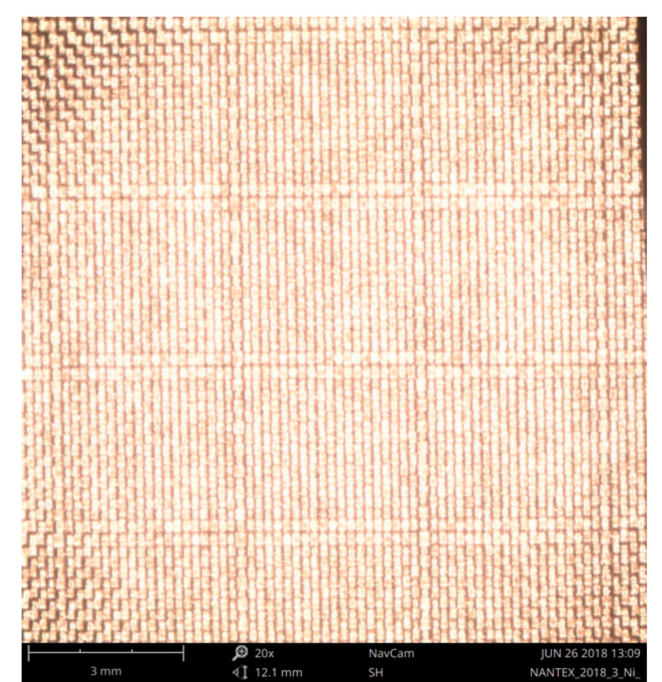

(a)

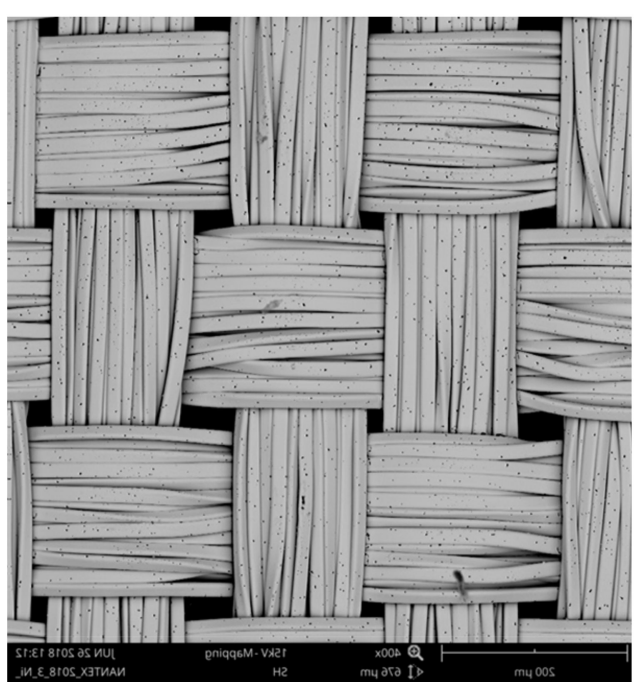

(b)

Figure 11. A sample of RSKCu+Ni (a), and detail of the sample structure (b). 
Figure 12 shows the measurement of the input parameters for the theoretical length of the warp and weft calculation using Equations (7) and (8). The length of the line connecting the arcs in warp and weft are marked $a$ and $b$, respectively. The sum of the radii of the warp and weft yarns $d_{\mathrm{s}}$ was obtained from the measurement of diameters of the warp and weft yarns, marked $d$-warp and $d$-weft, respectively. The warp interlacing angle $\Phi$ was obtained from measurement of the spacing of yarns, marked $M$; from calculation of the height of cylinder of yarns, Equation (6), i.e., parameters $M, d$-warp and $d$-weft were considered; and from calculation of the radius of yarns, i.e., parameters $d$-warp and $d$-weft were considered (Table 9). The theoretical length of the warp LWARP_CALC and the weft LWEFT_CALC was then calculated (Table 10). The length of the warp LWARP_MEAS was also measured (Figure 13 and Table 11).

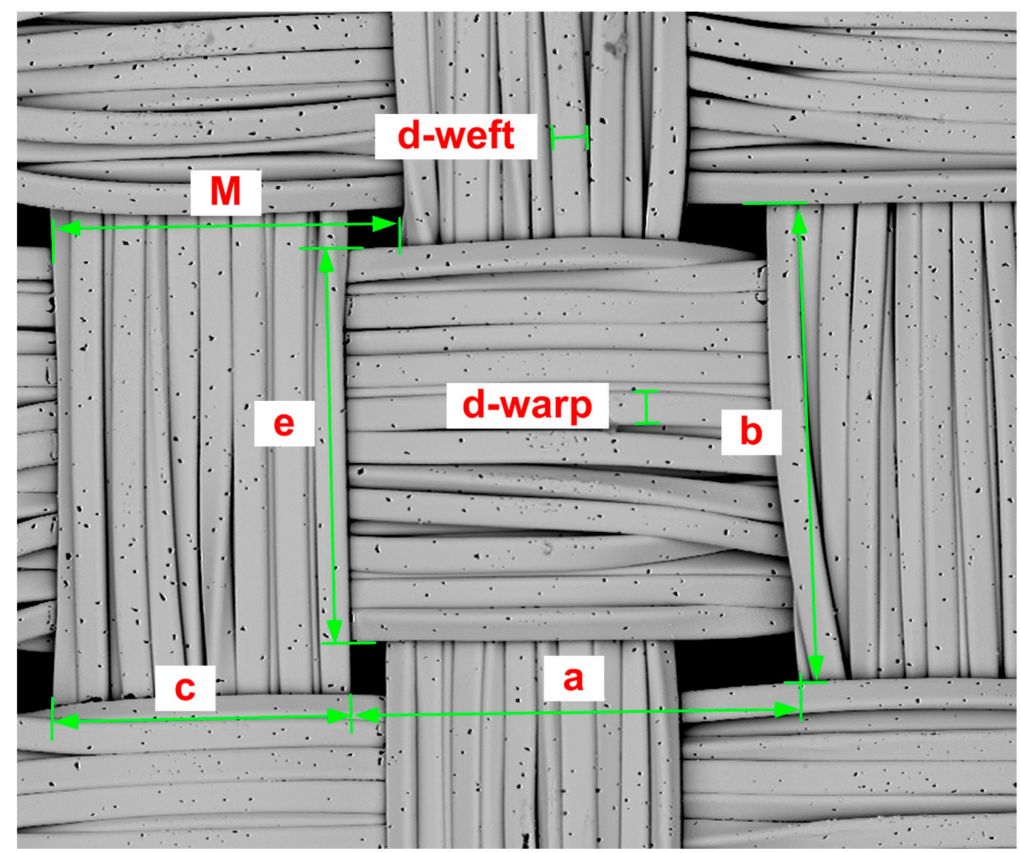

Figure 12. Measurement of input parameters for the theoretical length of the warp and weft calculation for the sample RSKCu+Ni.

Table 9. The measurement results of input parameters $a, b, c, e, \mathrm{M}, d$-warp, and $d$-weft-RSKCu+Ni.

\begin{tabular}{cccccccc}
\hline Meas. & $\boldsymbol{a}$ & $\boldsymbol{b}$ & $\boldsymbol{c}$ & $\boldsymbol{e}$ & $\boldsymbol{M}$ & $\boldsymbol{d}$-warp & $\boldsymbol{d}$-weft \\
\hline No. & $\mathbf{( m )}$ & $\mathbf{( m )}$ & $\mathbf{( m )}$ & $\mathbf{( m )}$ & $\mathbf{( m )}$ & $\mathbf{( m )}$ \\
\hline 1 & $1.99 \times 10^{-4}$ & $2.38 \times 10^{-4}$ & $1.46 \times 10^{-4}$ & $1.76 \times 10^{-4}$ & $1.74 \times 10^{-4}$ & $1.05 \times 10^{-5}$ & $1.02 \times 10^{-5}$ \\
2 & $2.07 \times 10^{-4}$ & $2.34 \times 10^{-4}$ & $1.41 \times 10^{-4}$ & $1.83 \times 10^{-4}$ & $1.72 \times 10^{-4}$ & $1.03 \times 10^{-5}$ & $1.00 \times 10^{-5}$ \\
3 & $2.07 \times 10^{-4}$ & $2.39 \times 10^{-4}$ & $1.53 \times 10^{-4}$ & $1.80 \times 10^{-4}$ & $1.70 \times 10^{-4}$ & $1.01 \times 10^{-5}$ & $1.05 \times 10^{-5}$ \\
4 & $2.06 \times 10^{-4}$ & $2.39 \times 10^{-4}$ & $1.44 \times 10^{-4}$ & $1.99 \times 10^{-4}$ & $1.69 \times 10^{-4}$ & $1.03 \times 10^{-5}$ & $1.01 \times 10^{-5}$ \\
5 & $2.06 \times 10^{-4}$ & $2.39 \times 10^{-4}$ & $1.41 \times 10^{-4}$ & $1.93 \times 10^{-4}$ & $1.69 \times 10^{-4}$ & $1.03 \times 10^{-5}$ & $1.01 \times 10^{-5}$ \\
6 & $2.08 \times 10^{-4}$ & $2.39 \times 10^{-4}$ & $1.48 \times 10^{-4}$ & $1.93 \times 10^{-4}$ & $1.67 \times 10^{-4}$ & $1.03 \times 10^{-5}$ & $1.02 \times 10^{-5}$ \\
7 & $2.10 \times 10^{-4}$ & $2.38 \times 10^{-4}$ & $1.51 \times 10^{-4}$ & $1.91 \times 10^{-4}$ & $1.66 \times 10^{-4}$ & $1.05 \times 10^{-5}$ & $1.09 \times 10^{-5}$ \\
8 & $2.12 \times 10^{-4}$ & $2.38 \times 10^{-4}$ & $1.47 \times 10^{-4}$ & $1.94 \times 10^{-4}$ & $1.64 \times 10^{-4}$ & $1.03 \times 10^{-5}$ & $1.01 \times 10^{-5}$ \\
9 & $2.15 \times 10^{-4}$ & $2.37 \times 10^{-4}$ & $1.53 \times 10^{-4}$ & $1.91 \times 10^{-4}$ & $1.61 \times 10^{-4}$ & $1.04 \times 10^{-5}$ & $1.07 \times 10^{-5}$ \\
10 & $2.15 \times 10^{-4}$ & $2.37 \times 10^{-4}$ & $1.42 \times 10^{-4}$ & $1.91 \times 10^{-4}$ & $1.61 \times 10^{-4}$ & $1.05 \times 10^{-5}$ & $1.03 \times 10^{-5}$ \\
Average & $2.09 \times 10^{-4}$ & $2.38 \times 10^{-4}$ & $1.47 \times 10^{-4}$ & $1.89 \times 10^{-4}$ & $1.67 \times 10^{-4}$ & $1.04 \times 10^{-5}$ & $1.03 \times 10^{-5}$ \\
Stand. deviation $\sigma$ & $4.50 \times 10^{-6}$ & $1.50 \times 10^{-6}$ & $4.41 \times 10^{-6}$ & $6.74 \times 10^{-6}$ & $4.10 \times 10^{-6}$ & $1.00 \times 10^{-7}$ & $3.00 \times 10^{-7}$ \\
\hline
\end{tabular}


Table 10. The modeling results for LWARP_CALC and LWEFT_CALC - RSKCu+Ni.

\begin{tabular}{ccc}
\hline Meas. & L WARP_CALC $_{\text {WEF }}$ & L $_{\text {WEFC }}$ \\
\hline No. & $\mathbf{( m )}$ & $\mathbf{( m )}$ \\
\hline 1 & $2.00 \times 10^{-4}$ & $2.13 \times 10^{-4}$ \\
2 & $2.08 \times 10^{-4}$ & $2.13 \times 10^{-4}$ \\
3 & $2.08 \times 10^{-4}$ & $2.13 \times 10^{-4}$ \\
4 & $2.07 \times 10^{-4}$ & $2.18 \times 10^{-4}$ \\
5 & $2.07 \times 10^{-4}$ & $2.23 \times 10^{-4}$ \\
6 & $2.09 \times 10^{-4}$ & $2.24 \times 10^{-4}$ \\
7 & $2.11 \times 10^{-4}$ & $2.26 \times 10^{-4}$ \\
8 & $2.13 \times 10^{-4}$ & $2.24 \times 10^{-4}$ \\
9 & $2.16 \times 10^{-4}$ & $2.21 \times 10^{-4}$ \\
10 & $2.16 \times 10^{-4}$ & $2.18 \times 10^{-4}$ \\
Average & $2.10 \times 10^{-4}$ & $2.19 \times 10^{-4}$ \\
Stand. deviation $\sigma$ & $4.60 \times 10^{-6}$ & $4.70 \times 10^{-6}$ \\
\hline
\end{tabular}

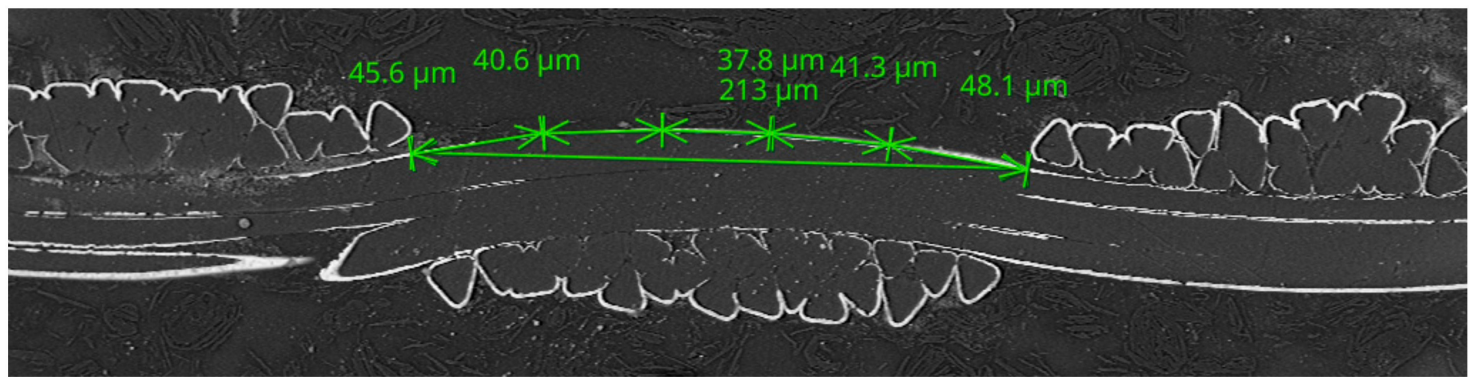

Figure 13. Measurement of the length of the warp for the sample RSKCu+Ni.

Table 11. The measurement results of the length of the warp $L_{\text {WARP_MEAS }}$ and the length of the line connecting the arcs in warp $a-\mathrm{RSKCu}+\mathrm{Ni}$.

\begin{tabular}{ccccccc}
\hline Meas. No. & & \multicolumn{3}{c}{$\begin{array}{c}\text { Measured Parts of the arc } \\
(\mathbf{m})\end{array}$} & \multicolumn{2}{c}{$\begin{array}{c}L_{\text {warp_MEAS }} \\
(\mathbf{m})\end{array}$} \\
\hline 1 & $4.56 \times 10^{-5}$ & $4.06 \times 10^{-5}$ & $3.78 \times 10^{-5}$ & $4.13 \times 10^{-5}$ & $4.81 \times 10^{-5}$ & $2.13 \times 10^{-4}$ \\
$(\mathbf{m})$
\end{tabular}

The theoretical warp length $L_{\text {WARP_CALC }}$ was $2.10 \times 10^{-4} \pm 4.58 \times 10^{-6} \mathrm{~m}$ and the measured warp length $L_{\text {WARP_MEAS }}$ was $2.14 \times 10^{-4} \pm 3.00 \times 10^{-7} \mathrm{~m}$. The ratio of $L_{\text {WARP_CALC }}$ and LWARP_MEAS is presented in Table 12. It also shows the difference in the units of percentage, i.e., the deformation of the yarns could be neglected, thus the circular shape of cross-section of warp and weft yarns of the Peirce's geometrical model of the interlacing point could be used. The theoretical warp lengths $L_{\text {WARP_CALC }}$ and $L_{\text {WEFT_CALC }}$ were inserted into Equations (9) and (10) to find $S_{\text {WARP }}$ and $S_{\text {WEFT, }}$, respectively. The surface area of the investigated Pierce's geometrical model of the sample $S_{\text {Effect }}$ was then obtained using Equation (12). The surface area of the investigated multifilament model of the sample RSKCu+Ni was then obtained using Equations (13) and (14) (Table 13). 
Table 12. The comparison of measurement and calculated results of the length of the warp-RSKCu+Ni.

\begin{tabular}{cccc}
\hline Meas. No. & $\boldsymbol{L}_{\text {warp_MEAS }}$ & $\boldsymbol{L}_{\text {warp_CALC }}$ & $\boldsymbol{L}_{\text {warp_MEAS }} / \boldsymbol{L}_{\text {warp_CALC }}$ \\
\hline & $\mathbf{( m )}$ & $\mathbf{( m )}$ & $\mathbf{( \% )}$ \\
\hline 1 & $2.13 \times 10^{-4}$ & $2.00 \times 10^{-4}$ & 106.50 \\
2 & $2.14 \times 10^{-4}$ & $2.08 \times 10^{-4}$ & 102.88 \\
3 & $2.14 \times 10^{-4}$ & $2.08 \times 10^{-4}$ & 102.88 \\
4 & $2.14 \times 10^{-4}$ & $2.07 \times 10^{-4}$ & 103.38 \\
5 & $2.14 \times 10^{-4}$ & $2.07 \times 10^{-4}$ & 103.38 \\
Average & $2.14 \times 10^{-4}$ & $2.06 \times 10^{-4}$ & 103.81 \\
Stand. deviation $\sigma$ & $3.00 \times 10^{-7}$ & $3.02 \times 10^{-6}$ & 1.36 \\
\hline
\end{tabular}

Table 13. The modeling results for $\mathrm{RSKCu}+\mathrm{Ni}$.

\begin{tabular}{ccc}
\hline Parameter & Average & Standard Deviation \\
\hline$L_{\text {WARP_CALC }}(\mathrm{m})$ & $2.10 \times 10^{-4}$ & $4.58 \times 10^{-6}$ \\
$L_{\text {WEFT_CALC }}(\mathrm{m})$ & $2.39 \times 10^{-4}$ & $1.50 \times 10^{-6}$ \\
$S_{\text {WARP }}\left(\mathrm{m}^{2}\right)$ & $6.82 \times 10^{-15}$ & $1.80 \times 10^{-16}$ \\
$S_{\text {WEFT }}\left(\mathrm{m}^{2}\right)$ & $7.73 \times 10^{-15}$ & $2.20 \times 10^{-16}$ \\
$S_{\text {Inter_point }}\left(\mathrm{m}^{2}\right)$ & $1.70 \times 10^{-16}$ & $1.00 \times 10^{-17}$ \\
$S_{\text {Effect }}\left(\mathrm{m}^{2}\right)$ & $7.11 \times 10^{-15}$ & $1.60 \times 10^{-16}$ \\
S1 $_{\text {WARP_Multi }}\left(\mathrm{m}^{2}\right)$ & $4.88 \times 10^{-14}$ & $1.07 \times 10^{-15}$ \\
S2 $_{\text {WEFT_Multi }}\left(\mathrm{m}^{2}\right)$ & $4.30 \times 10^{-14}$ & $2.60 \times 10^{-16}$ \\
\hline
\end{tabular}

\subsection{Relative Comparison of Surface Areas of Samples Using the Electrochemical Method}

The surface area of the Cu plate, RSKCuIv4, CerexCuIv4, and RSKCu+Ni was evaluated using the comparative measurement method described in Section 2.4. Table 14 and Figure 14 show measurement results of the resistance between the first (base) electrode, i.e., $\mathrm{Cu}$ plate, and the second electrode, i.e., $\mathrm{Cu}$ plate, $\mathrm{RSKCuIv4}$, CerexCuIv4, and $\mathrm{RSKCu}+\mathrm{Ni}$. The resistance results were inserted into Equation (16) and surface areas were obtained (Table 14).

Table 14. The measurement results of the resistance between two electrodes: $\mathrm{Cu}$ plate $+(\mathrm{Cu}$ plate, CerexCuIv4, RSKCu+Ni, or RSKCuIv4).

\begin{tabular}{|c|c|c|c|c|}
\hline \multirow{2}{*}{$\begin{array}{l}\text { Distance between Electrodes } \\
\text { (m) }\end{array}$} & \multicolumn{4}{|c|}{ Resistance $(\Omega)$} \\
\hline & Cu plate & RSKCuIv4 & CerexCuIv4 & $\mathrm{RSKCu}+\mathrm{Ni}$ \\
\hline $1.00 \times 10^{-2}$ & $6.5 \times 10^{-1}$ & $6.9 \times 10^{-1}$ & $6.4 \times 10^{-1}$ & $6.3 \times 10^{-1}$ \\
\hline $2.00 \times 10^{-2}$ & $1.2 \times 10^{-2}$ & $1.2 \times 10^{-2}$ & $1.2 \times 10^{-2}$ & $1.1 \times 10^{-2}$ \\
\hline $3.00 \times 10^{-2}$ & $1.7 \times 10^{-2}$ & $1.6 \times 10^{-2}$ & $1.6 \times 10^{-2}$ & $1.5 \times 10^{-2}$ \\
\hline $4.00 \times 10^{-2}$ & $2.0 \times 10^{-2}$ & $1.9 \times 10^{-2}$ & $1.9 \times 10^{-2}$ & $1.8 \times 10^{-2}$ \\
\hline $5.00 \times 10^{-2}$ & $2.2 \times 10^{-2}$ & $2.1 \times 10^{-2}$ & $2.1 \times 10^{-2}$ & $2.1 \times 10^{-2}$ \\
\hline \multirow[t]{2}{*}{$10.00 \times 10^{-2}$} & $3.1 \times 10^{-2}$ & $3.1 \times 10^{-2}$ & $3.2 \times 10^{-2}$ & $3.0 \times 10^{-2}$ \\
\hline & & \multicolumn{3}{|c|}{ Surface area $\left(\mathrm{m}^{2}\right)$} \\
\hline Average & $3.06 \times 10^{-3}$ & $3.18 \times 10^{-3}$ & $3.22 \times 10^{-3}$ & $3.28 \times 10^{-3}$ \\
\hline Stand. deviation $\sigma$ & $0.00 \times 10^{0}$ & $4.50 \times 10^{-5}$ & $8.22 \times 10^{-5}$ & $7.48 \times 10^{-5}$ \\
\hline
\end{tabular}




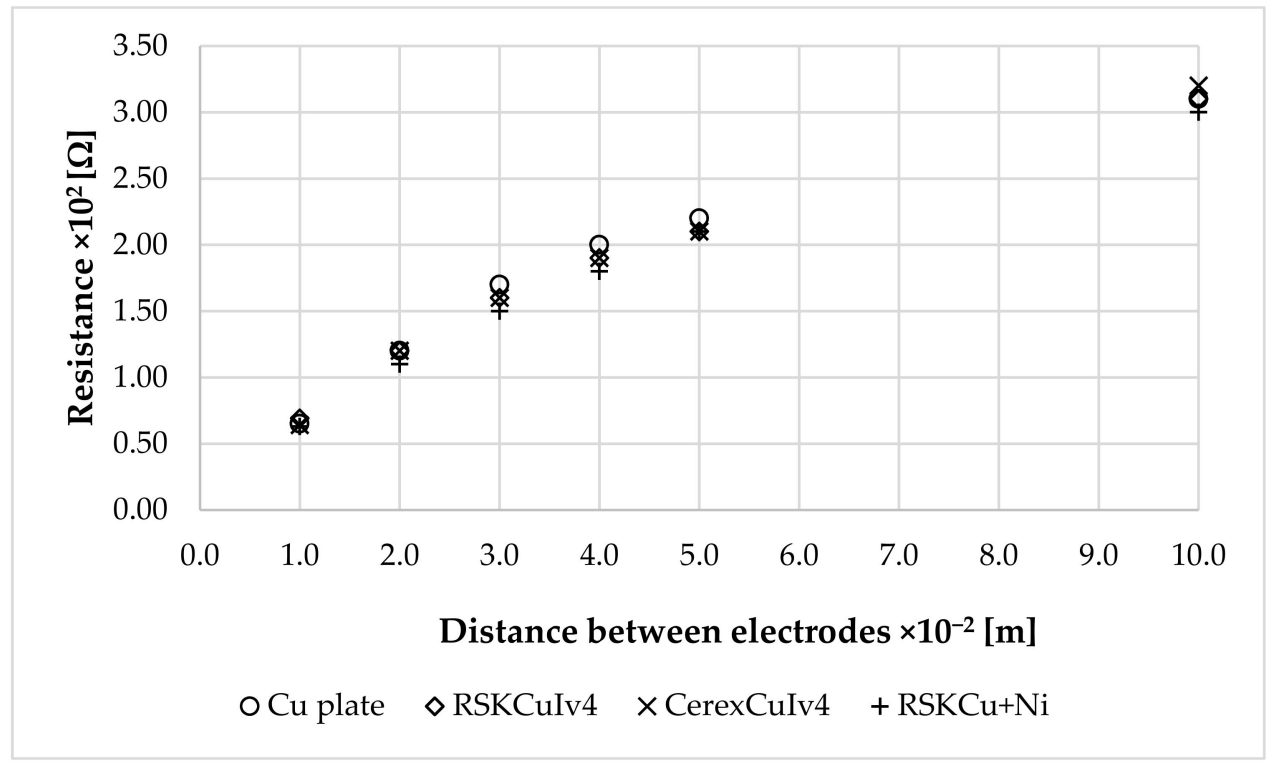

Figure 14. Measurement results of the resistance values in relation to the distance between electrodes.

Resistance values increased with the increased distance between electrodes. This corresponded with the theory as shown in Equation (16), i.e., the surface area was obtained for each sample. The largest surface area was obtained for $\mathrm{RSKCu}+\mathrm{Ni}$, followed by CerexCuIv4. The lowest surface area was obtained for RSKCuIv4.

\subsection{Summary of the Surface Area Evaluation}

The theoretical warp length $L_{\text {WARP_CALC }}$ was $2.01 \times 10^{-4} \pm 3.00 \times 10^{-6} \mathrm{~m}$ and the measured warp length $L_{\text {WARP_MEAS }}$ was $2.07 \times 10^{-4} \pm 3.09 \times 10^{-6} \mathrm{~m}$ for the RSKCuIv4. The theoretical warp length $L_{\text {WARP_CALC }}$ was $2.10 \times 10^{-4} \pm 4.58 \times 10^{-6} \mathrm{~m}$ and the measured warp length

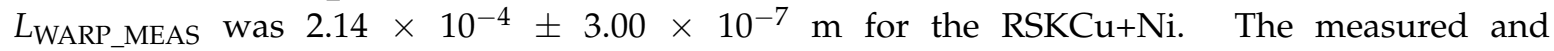
the calculated values did not differ from each other within the standard deviation, and the theoretical warp lengths LWARP_CALC and LWEFT_CALC were inserted into Equations (9) and (10) to find the surface area of the warp $S_{\text {WARP }}$ and weft $S_{\text {WEFT }}$. The surface area of the investigated Pierce's geometrical model $S_{\text {effect }}$ for monofilament (non-fibrous) yarns was then calculated for RSKCuIv4 to be $6.73 \times 10^{-15} \pm 1.30 \times 10^{-16} \mathrm{~m}^{2}$ and $7.11 \times 10^{-15} \pm 1.60 \times 10^{-16} \mathrm{~m}^{2}$ for RSKCu+Ni. The surface area of multifilament yarns in warp $S_{1}$ and weft $S_{2}$ was determined for RSKCuIv4 to be $S_{1}=6.50 \times 10^{-14} \pm 1.03 \times 10^{-15} \mathrm{~m} 2$ and $S_{2}=4.74 \times 10^{-14} \pm 1.03 \times 10^{-15} \mathrm{~m}^{2}$, and $S_{1}=4.88 \times 10^{-14} \pm 1.07 \times 10^{-15} \mathrm{~m}^{2}$ and $S_{2}=4.30 \times 10^{-14} \pm 2.60 \times 10^{-16} \mathrm{~m}^{2}$ for RSKCu+Ni.

The surface area of $\mathrm{Cu}$ plate, RSKCuIv4, CerexCuIv4, and RSKCu+Ni was evaluated using the comparative calculation. The results from the individual surface area of the presented models of samples $S_{1}$ and $S_{2}$ were recalculated to a uniform surface area $S_{\text {default }} 3.06 \times 10^{-3} \mathrm{~m}^{2}$ using Equation (17) (Table 15).

$$
S_{\text {Surface_area_model }}=\left(S_{1}+S_{2}\right) * \frac{S_{\text {default }}}{S_{\text {background }}} .
$$

where $S_{\text {default }}$ is the surface area about size $3.06 \times 10^{-3} \mathrm{~m}^{2}$ and $S_{\text {background }}$ is the surface area under of Peirce's geometrical model of the interlacing point of individual samples.

Modeling results of the surface area of samples shown in Table 15 were compared with the measurement results shown in Table 14 (Figure 15). 
Table 15. The modeling results for surface area of samples.

\begin{tabular}{cccc}
\hline Modeling & RSKCuIv4 & CerexCuIv4 & RSKCu+Ni \\
\hline No. & $\mathbf{( m}^{\mathbf{2}}$ & $\mathbf{( m}^{\mathbf{2}}$ & $\mathbf{( m}^{\mathbf{2}}$ \\
\hline 1 & $4.65 \times 10^{-3}$ & $5.37 \times 10^{-3}$ & $5.78 \times 10^{-3}$ \\
2 & $4.67 \times 10^{-3}$ & $5.36 \times 10^{-3}$ & $5.73 \times 10^{-3}$ \\
3 & $4.69 \times 10^{-3}$ & $5.31 \times 10^{-3}$ & $5.66 \times 10^{-3}$ \\
4 & $4.67 \times 10^{-3}$ & $5.43 \times 10^{-3}$ & $5.68 \times 10^{-3}$ \\
5 & $4.64 \times 10^{-3}$ & $5.33 \times 10^{-3}$ & $5.68 \times 10^{-3}$ \\
6 & $4.64 \times 10^{-3}$ & $5.36 \times 10^{-3}$ & $5.66 \times 10^{-3}$ \\
7 & $4.60 \times 10^{-3}$ & $5.32 \times 10^{-3}$ & $5.65 \times 10^{-3}$ \\
8 & $4.59 \times 10^{-3}$ & $5.36 \times 10^{-3}$ & $5.62 \times 10^{-3}$ \\
9 & $4.58 \times 10^{-3}$ & $5.41 \times 10^{-3}$ & $5.60 \times 10^{-3}$ \\
10 & $4.61 \times 10^{-3}$ & $5.36 \times 10^{-3}$ & $5.60 \times 10^{-3}$ \\
Average & $4.63 \times 10^{-3}$ & $5.36 \times 10^{-3}$ & $5.67 \times 10^{-3}$ \\
Stand. deviation $\sigma$ & $3.62 \times 10^{-5}$ & $3.54 \times 10^{-5}$ & $5.23 \times 10^{-5}$ \\
\hline
\end{tabular}

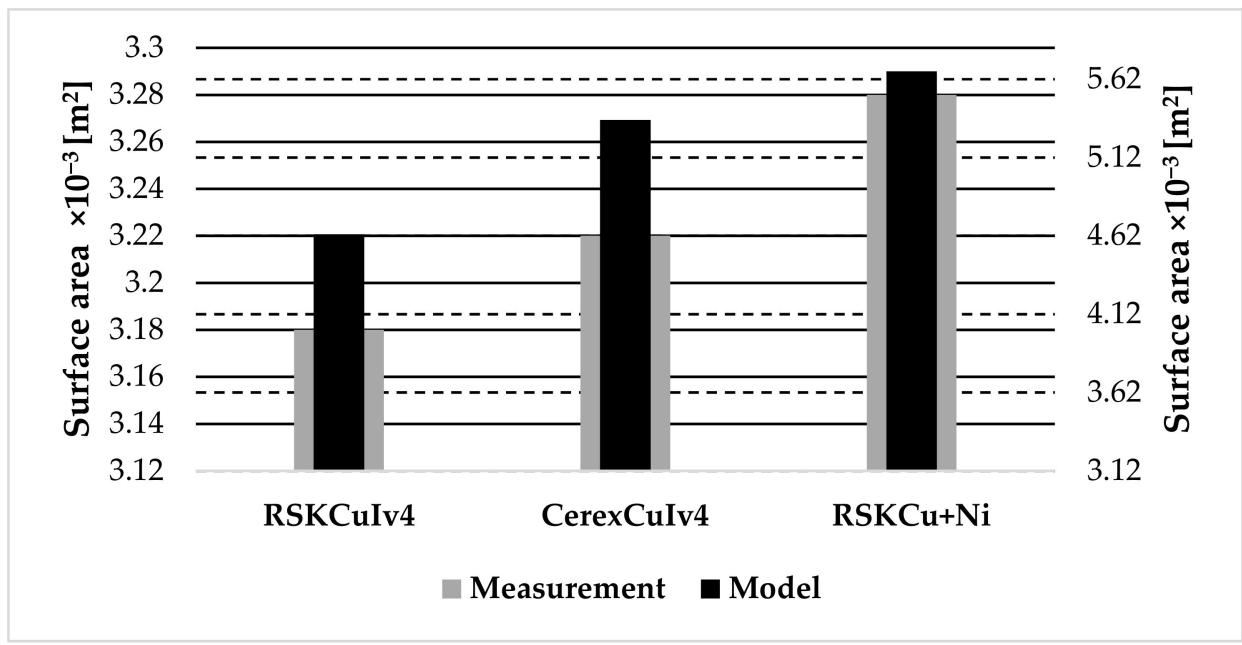

Figure 15. Comparison of modeling and measurement results of the surface area of samples.

The surface area of RSKCuIv4 was evaluated to be $S_{\text {model_RSKCuIv4 }}=4.63 \times 10^{-3} \pm 3.62 \times 10^{-5} \mathrm{~m}^{2}$ and $S_{\text {measurement_RSKCuIv4 }}=3.18 \times 10^{-3} \pm 4.50 \times 10^{-5} \mathrm{~m}^{2}$. The surface area of CerexCuIv4 was evaluated to be $S_{\text {model_CerexCuIv4 }}=5.36 \times 10^{-3} \pm 3.54 \times 10^{-5} \mathrm{~m}^{2}$ and emphS $S_{\text {measurement_CerexCuIv4 }}=3.22 \times 10^{-3} \pm 8.22 \times 10^{-5} \mathrm{~m}^{2}$. The surface area of $\mathrm{RSKCu}+\mathrm{Ni}$ was evaluated to be $S_{\text {model_RSKCu+Ni }}=5.67 \times 10^{-3} \pm 5.23 \times 10^{-5} \mathrm{~m}^{2}$ and $S_{\text {measurement_RSKCu+Ni }}=3.28 \times 10^{-3} \pm 7.48 \times 10^{-5} \mathrm{~m}^{2}$. The modeling results for the surface area evaluations of the samples showed an increasing trend, i.e., the surface area of the RSKCuIv4 was the smallest surface area of investigated samples, followed by the surface area of the CerexCuIv4, and by RSKCu+Ni. This increasing trend, i.e., the surface area of the RSKCuIv4 was the smallest one, followed by CerexCuIv4 and by RSKCu+Ni, was also shown using the experimental electrochemical method. Both the modeled and the measured surface areas were larger than the uniform surface area, i.e., the sample $\mathrm{Cu}$ plate, which corresponded to the theory that the coated polymer-based textiles have a larger surface area than the standard metal plate. The measurement results were of the same order as the modeling results, but showed higher values. This was caused by the used method, which is suitable only for the relative comparison of surface area values as described in Section 2.4.

\section{Conclusions}

Calculation of the surface area of coated woven and non-woven textiles finds its application in development of electrical and electrochemical components and devices such as supercapacitors, 
electrochemical cells, and electrochemical catalysts. In this paper, several methods for the real effective surface area evaluation of coated woven and non-woven polymer-based textiles were presented. The proposed model for woven textiles was based on Pierce's geometrical model and on the evaluation of samples by optical methods. The evaluation of non-woven textiles was performed using optical methods and image processing methods. All these proposed models were compared with an experimental electrochemical method for surface area evaluation measurement. The experimental results confirmed the results obtained from modeling. The results show that the largest effective surface area was obtained for copper- and nickel-plated woven polyester fabric and the lowest was obtained for copper- and acrylic-coated woven polyester fabric.

Author Contributions: All authors contributed to the writing of the article. All authors contributed to computations and models. L.V. and K.D. designed and made an experimental verification of the model.

Funding: This research was funded by the Ministry of Industry and Trade grant number FV30171.

Conflicts of Interest: The authors declare no conflict of interest.

\section{References}

1. Šafářová, V.; Militký, J. Multifunctional metal composite textile shields against electromagnetic radiation-Effect of various parameters on electromagnetic shielding effectiveness. Polym. Compos. 2017, 38, 309-323. [CrossRef]

2. Vojtech, L.; Neruda, M. Design of radiofrequency protective clothing containing silver nanoparticles. Fibres Text. East. Eur. 2013, 5, 141-147.

3. Lopez, A.; Vojtech, L.; Neruda, M. Comparison among models to estimate the shielding effectiveness applied to conductive textiles. Adv. Electr. Electron. Eng. 2013, 11, 387-391. [CrossRef]

4. Neruda, M.; Vojtech, L.; Rohlik, M.; Hajek, J.; Holý, R.; Kalika, M. Application of shielding textile materials in electric vehicles. In Proceedings of the 24th Wireless and Optical Communication Conference (WOCC), Taipei, Taiwan, 23-24 October 2015.

5. Mahltig, B.; Zhang, J.; Wu, L.; Darko, D.; Wendt, M.; Lempa, E.; Rabe, M.; Haase, H. Effect pigments for textile coating: a review of the broad range of advantageous functionalization. J. Coat. Technol. Res. 2017, 14, 35-55. [CrossRef]

6. Vojtech, L.; Neruda, M. Modelling of surface and bulk resistance for wearable textile antenna design. Prz. Elektrotech. 2013, 89, 217-222.

7. Ferreira, D.; Pires, P.; Rodrigues, R.; Caldeirinha, R.F. Wearable textile antennas: Examining the effect of bending on their performance. IEEE Antennas Propag. Mag. 2017, 59, 54-59. [CrossRef]

8. Singh, N.K.; Singh, V.K.; Naresh, B. Textile antenna for microwave wireless power transmission. Procedia Comput. Sci. 2016, 85, 856-861. [CrossRef]

9. Vojtech, L.; Bortel, R.; Neruda, M.; Kozak, M. Wearable textile electrodes for ECG measurement. Adv. Electr. Electron. Eng. 2013, 11, 410-414. [CrossRef]

10. Liu, M.; Pu, X.; Jiang, C.; Liu, T.; Huang, X.; Chen, L.; Du, C.; Sun, J.; Hu, W.; Wang, Z.L. Large-Area All-Textile Pressure Sensors for Monitoring Human Motion and Physiological Signals. Adv. Mater. 2017, 29, 1703700. [CrossRef] [PubMed]

11. Zhou, G.; Byun, J.H.; Oh, Y.; Jung, B.M.; Cha, H.J.; Seong, D.G.; Um, M.K.; Hyun, S.; Chou, T.W. Highly sensitive wearable textile-based humidity sensor made of high-strength, single-walled carbon nanotube/poly (vinyl alcohol) filaments. ACS Appl. Mater. Interfaces 2017, 9, 4788-4797. [CrossRef] [PubMed]

12. Laforgue, A. All-textile flexible supercapacitors using electrospun poly(3,4-ethylenedioxythiophene) nanofibers. J. Power Sources 2011, 196, 559-564. [CrossRef]

13. Zhang, Z.; Guo, K.; Li, Y.; Li, X.; Guan, G.; Li, H.; Luo, Y.; Zhao, F.; Zhang, Q.; Wei, B.; et al. A colour-tunable, weavable fibre-shaped polymer light-emitting electrochemical cell. Nat. Photonics 2015, 9, 233. [CrossRef]

14. Vojtech, L.; Hajek, J.; Neruda, M.; Zatloukal, M. Monometallic textile electrodes for "green" batteries. Elektron. Elektrotech. 2014, 20, 25-28. [CrossRef]

15. Reddy, T.B.; Linden, D. Linden's Handbook of Batteries, 4th ed.; McGraw-Hill Education: New York, NY, USA, 2010. 
16. Grancarić, A.M.; Jerković, I.; Koncar, V.; Cochrane, C.; Kelly, F.M.; Soulat, D.; Legrand, X. Conductive polymers for smart textile applications. J. Ind. Text. 2018, 48, 612-642. [CrossRef]

17. Tian, Y.; Wu, J. A comprehensive analysis of the BET area for nanoporous materials. AIChE J. 2018, 64, $286-293$. [CrossRef]

18. De Lange, M.F.; Thijs, J.H.V.; Gascon, J.; Kapteijn, F. Adsorptive characterization of porous solids: Error analysis guides the way. Microporous Mesoporous Mater. 2014, 200, 199-215. [CrossRef]

19. Non-Woven Metallized Textiles. Available online: https://lorix.hu/en/products/non-woven-metallizedtextile (accessed on 30 July 2018).

20. RS Type Metallized Fabrics. Available online: https://lorix.hu/en/products/rs-type-metallized-fabrics (accessed on 30 July 2018).

21. Peirce, F.T. 5-The geometry of cloth structure. J. Text. Inst. Trans. 1937, 28, T45-T96. [CrossRef]

22. Dvořák, J.; Karel, P.; Žák, J. Study of Interactions between Weaving Process and Weaving Machine Systems; VÚTS, a.s.: Liberec, Czech Republic, 2018.

23. Bartoš, P.; Špatenka, P.; Volfová, L. Deposition of $\mathrm{TiO}_{2}$-Based Layer on Textile Substrate: Theoretical and Experimental Study. Plasma Process. Polym. 2009, 6, 897-901. [CrossRef]

24. Create Draggable, Resizable Line. Available online: http://www.mathworks.com/help/images/ref/imline. html (accessed on 20 July 2018).

25. Create Draggable Freehand Region. Available online: http://www.mathworks.com/help/images/ref/ imfreehand.html (accessed on 20 July 2018).

26. Volume Enclosed by a Cylinder. Available online: http://www.mathopenref.com/cylindervolume.html (accessed on 20 July 2018).

27. Open Image Viewer app. Available online: http://www.mathworks.com/help/images/ref/imtool.html (accessed on 20 July 2018).

28. Crop Image. Available online: http://www.mathworks.com/help/images/ref/imcrop.html (accessed on 20 July 2018).

(C) 2018 by the authors. Licensee MDPI, Basel, Switzerland. This article is an open access article distributed under the terms and conditions of the Creative Commons Attribution (CC BY) license (http:/ / creativecommons.org/licenses/by/4.0/). 